\title{
Arabidopsis ETHYLENE RESPONSE FACTOR 8 (ERF8) has dual functions in ABA signaling and immunity
}

\author{
Feng Yi Cao', Thomas A. DeFalco ${ }^{1,5}$, Wolfgang Moeder ${ }^{1}$, Bo Li², Yunchen Gong ${ }^{1,3}$, Xiao-Min Liu, \\ Masatoshi Taniguchi ${ }^{1,7}$, Shelley Lumba ${ }^{1}$, Shigeo Toh ${ }^{1,6}$, Libo Shan ${ }^{2}$, Brian Ellis ${ }^{4}$, Darrell Desveaux ${ }^{1,3^{*}}$ and \\ Keiko Yoshioka ${ }^{1,3^{*}}$
}

\begin{abstract}
Background: ETHYLENE RESPONSE FACTOR (ERF) 8 is a member of one of the largest transcription factor families in plants, the APETALA2/ETHYLENE RESPONSIVE FACTOR (AP2/ERF) superfamily. Members of this superfamily have been implicated in a wide variety of processes such as development and environmental stress responses.

Results: In this study we demonstrated that ERF8 is involved in both ABA and immune signaling. ERF8 overexpression induced programmed cell death (PCD) in Arabidopsis and Nicotiana benthamiana. This PCD was salicylic acid (SA)-independent, suggesting that ERF8 acts downstream or independent of SA. ERF8-induced PCD was abolished by mutations within the ERF-associated amphiphilic repression (EAR) motif, indicating ERF8 induces cell death through its transcriptional repression activity. Two immunity-related mitogen-activated protein kinases, MITOGEN-ACTIVATED PROTEIN KINASE 4 (MPK4) and MPK11, were identified as ERF8-interacting proteins and directly phosphorylated ERF8 in vitro. Four putative MPK phosphorylation sites were identified in ERF8, one of which (Ser103) was determined to be the predominantly phosphorylated residue in vitro, while mutation of all four putative phosphorylation sites partially suppressed ERF8-induced cell death in N. benthamiana. Genome-wide transcriptomic analysis and pathogen growth assays confirmed a positive role of ERF8 in mediating immunity, as ERF8 knockdown or overexpression lines conferred compromised or enhanced resistance against the hemibiotrophic bacterial pathogen Pseudomonas syringae, respectively.
\end{abstract}

Conclusions: Together these data reveal that the ABA-inducible transcriptional repressor ERF8 has dual roles in ABA signaling and pathogen defense, and further highlight the complex influence of $A B A$ on plant-microbe interactions.

Keywords: ERF, Ethylene response factor, Cell death, Map kinase, MPK4, MPK11, ERF8, MITOGEN-ACTIVATED PROTEIN KINASE, ABA

\section{Background}

Sophisticated cellular signaling pathways govern plant responses to diverse environmental stimuli. The phytohormones salicylic acid (SA), ethylene, and jasmonic acid (JA), play important roles in plant immunity [1]. In particular, SA plays a well-documented and critical role in promoting defense responses to biotrophic pathogens [2]. While less characterized, defense-related roles for other

\footnotetext{
*Correspondence: darrell.desveaux@utoronto.ca; keiko.yoshioka@utoronto.ca ${ }^{1}$ Department of Cell and Systems Biology, University of Toronto, 25 Willcocks Street, Toronto, ON M5S 3B2, Canada

Full list of author information is available at the end of the article
}

phytophormones, including auxin, gibberellic acid (GA), and abscisic acid (ABA), have also been documented [1]. $\mathrm{ABA}$, in particular, has been thoroughly characterized as regulating both responses to abiotic stresses, such as drought, salinity, and cold, and developmental processes such as germination [3, 4]; however, recent evidence suggests that $\mathrm{ABA}$ also plays a complex role in regulating plant immunity [5].

Immunity-related phenotypes have been previously documented for several ABA-related mutants, including the ABA receptors PYRABACTIN RESISTANT-LIKE 8 (PYL8), PYL10 and PYL11, the protein phosphatase 2C

(c) The Author(s). 2018 Open Access This article is distributed under the terms of the Creative Commons Attribution 4.0 International License (http://creativecommons.org/licenses/by/4.0/), which permits unrestricted use, distribution, and 
(PP2C) HYPERSENSITIVE TO ABA1 (HAB1), SNF1-RELATED KINASE 2.6 (SNRK2.6), as well as the ABA biosynthesis genes $A B A D E F I C I E N T 1$ (ABA1), ABA2 and $A B A 3$ [6-8]. The influence of ABA on the outcome of plant-pathogen interaction is also dependent on the pathosystem of study, the method of ABA application, the mode and stage of pathogen infection, and many other factors $[9,10]$. Although the molecular mechanisms by which ABA influences immunity are not well understood $[5,9]$, multiple points of antagonism between $A B A$ and SA signaling have been reported, suggesting that $A B A$ may suppress immunity via suppression of SA signaling [11-14]. While ABA-SA antagonism likely emerges from multiple points of crosstalk [15], empirical study of such points remains minimal. A refined understanding of ABA-SA antagonism can thus provide valuable insight into the balance between abiotic and biotic stress signaling pathways.

Plants are able to defend themselves against most microbes by recognizing conserved microbe- or pathogen-associated molecular patterns (MAMPs or PAMPs, respectively) via a suite of cell-surface pattern recognition receptors (PRRs) [16]. Recognition of MAMPs/ PAMPs by their cognate PRRs activates a cascade of intracellular signaling, ultimately leading to pattern-triggered immunity (PTI), which is sufficient to prevent the proliferation of most potential pathogenic microbes [16]. To maintain virulence, some pathogens have evolved effector proteins that perturb host cellular processes and ultimately dampen defense. The hemibiotrophic bacterial pathogen Pseudomonas syringae, for example, utilizes a type III secretion system to deliver effectors into the plant cell [17, 18], and phytohormone signaling pathways have been identified as targets of effectors from multiple pathogens $[5,17,19]$. For example, the $P$. syringae effectors AvrPtoB and HopAM1 activate $\mathrm{ABA}$ signaling to promote bacterial virulence, although the specific molecular mechanisms involved remain unknown [20, 21]. The outcome of plant-pathogen interactions largely depends on the ability of plants to directly or indirectly recognize effector proteins, as such recognition elicits a secondary layer of defense responses, known as effector-triggered immunity (ETI) [22, 23]. A characteristic ETI response against biotrophic pathogens is the establishment of robust programmed cell death (PCD) at the site of infection, known as the hypersensitive response (HR), which is thought to isolate invading pathogens in the dead cell clusters and prevent systemic infection [24].

Transcription factors are crucial and common elements in signaling pathways involved in abiotic and biotic stresses responses [25-27]. One of the largest transcription factor families in plants, the APETALA2/ETHYLENE RESPONSIVE FACTOR (AP2/ERF) transcription factor superfamily, is characterized by one or more conserved N-terminal ERF DNA binding domain(s). Members of this superfamily have been implicated in a wide variety of processes, including development and environmental stress responses, as well as hormone signaling and pathogen defense [25, 28, 29]. Notably, specific members of group VII, VIII and predominantly group IX within the ERF family have been shown to play a role in Arabidopsis immunity [29-32]. The class II ERF transcriptional repressors, part of group VIII ERFs (subgroup a), are characterized by one of the most abundant repression motif in plants, the ERF-associated amphiphilic repression (EAR) motif -L/FDLNL/F(x)P [3335]. This small group of EAR motif-containing ERFs has 8 members in Arabidopsis, with limited functional characterization. ERF4 contributes to senescence (together with ERF8) as well as susceptibility to the necrotrophic fungal pathogen Fusarium oxysporum [36, 37], ERF9 contributes to resistance against the necrotrophic fungus, Botrytis cinerea [38], while ERF7 and ERF11 may be part of the transcriptional repressor complex in ABA or ethylene and GA signaling, respectively [39-41]. Interestingly, one member of this subfamily, ERF8, is part of the complex network of protein-protein interactions that are transcriptionally regulated by $A B A$ [42], and as such is expected to play a role in ABA signaling.

Here, we demonstrated a role of ERF8 in both ABA-mediated responses and immunity. We found that over-expression of ERF8 is sufficient to induce PCD-like cell death, and that ERF8 positively regulates immunity against $P$. syringae. Moreover, ERF8 interacts with and is phosphorylated by two immunity-related mitogen-activated protein (MAP) kinases (MPKs), MPK4 and MPK11. Both MPK4 and MPK11 are activated by bacterial PAMPs [43, 44], while MPK4 has also been demonstrated to be important for many SA-dependent pathogen defense responses [45-47]. RNA-Seq analysis showed ERF8 overexpression leads to transcriptional changes of genes involved in ABA signaling as well as pathogen defense and cell death regulation. Hence, ERF8 represents a potential point of crosstalk between ABA-mediated abiotic stress responses and SA-mediated pathogen defense.

\section{Results}

ERF8 is a negative regulator of ABA-mediated responses

ERF8 has previously been shown to be a component of the transcriptionally-regulated ABA interactome network [42], suggestive of a role in ABA signaling. Furthermore, microarray data indicated an increase in $E R F 8$ expression during germination (Additional file 1A) [48]. Thus, to examine the role of ERF8 in ABA signaling, ABA-mediated seed germination inhibition assays were performed with ERF8 gain-of-function and loss-of-function mutant seeds. For these assays we used the confirmed ERF8 knockdown line FLAG157D10 [36], hereafter referred to as erf8-1 (Ws-2 background), as well as dexamethasone (DEX)-inducible $E R F 8$ overexpression lines (ERF8-OE, Col-0 background). 
Over-expression of ERF8 after DEX treatment of these lines was confirmed by Western blot (Additional file 1b). As shown in Fig. 1, erf8-1 seeds showed increased sensitivity to ABA (Fig. 1a, b) while ERF8-OE seeds showed decreased sensitivity (Fig. 1c, d), indicating a negative role of ERF8 in ABA-mediated germination and seedling establishment.

\section{ERF8 overexpression induces programmed cell death} (PCD) in a. Thaliana and N. Benthamiana

It was previously reported that constitutive expression of ERF8 causes lesions in cotyledons and true leaves and associated with a higher rate of premature death before flowering [36]. Thus, we characterized cell death associated with ERF8 in DEX-inducible ERF8-OE lines. As shown in Fig. 2, both micro- and macroscopic PCD was clearly observed 2 days post DEX treatment (Fig. 2a, b). Moreover, cell death induction was also observed after Agrobacterium-mediated transient overexpression of ERF8 in Nicotiana benthamiana 3 days post infiltration (Fig. 2c). HR cell death is a well-described, SA-dependent form of defense-related PCD that is often observed after infection with avirulent biotrophic and hemibiotrophic pathogens $[49,50]$. To test the SA-dependency of ERF8-induced cell death, DEX-inducible ERF8 overexpression lines were

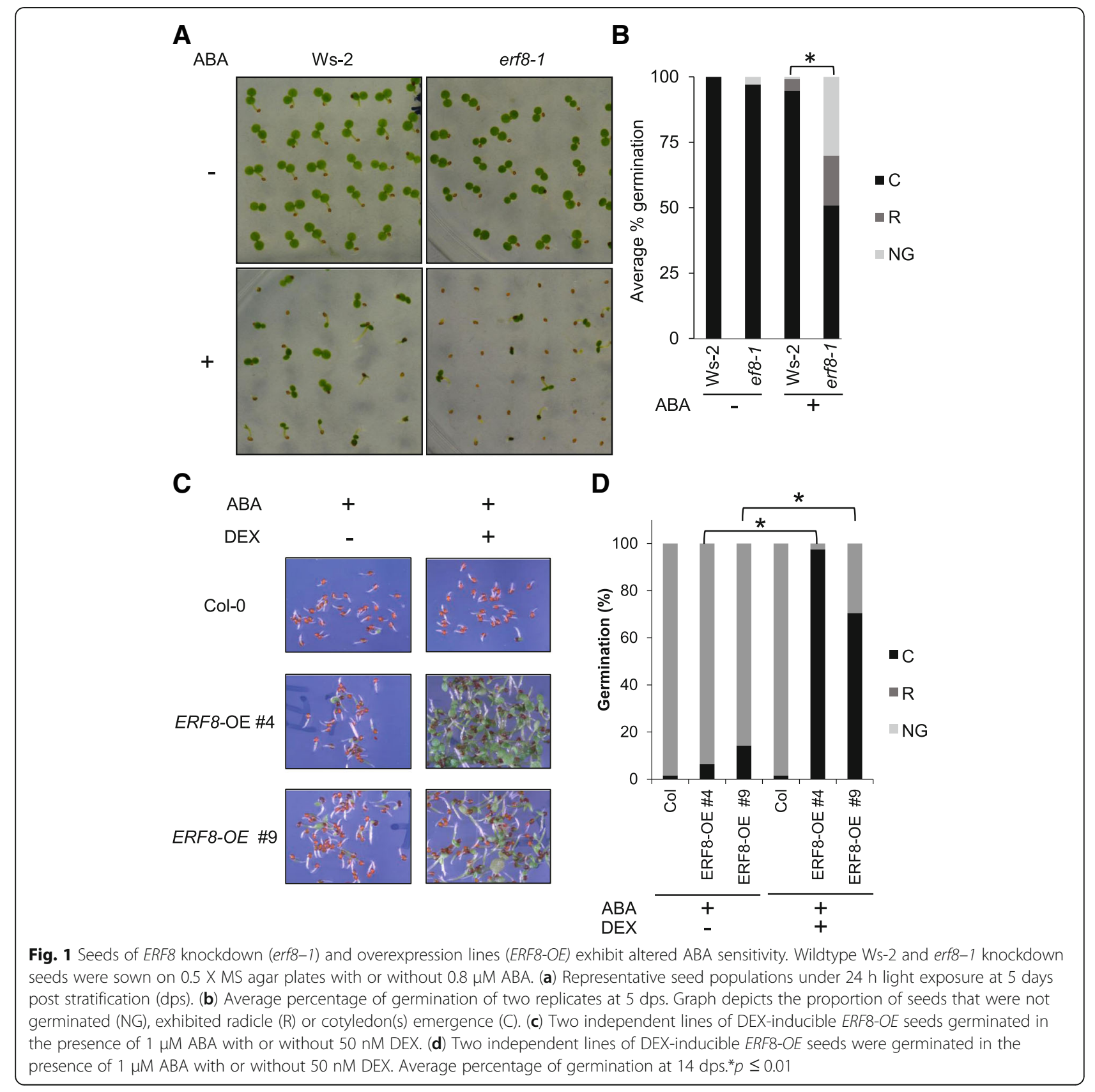




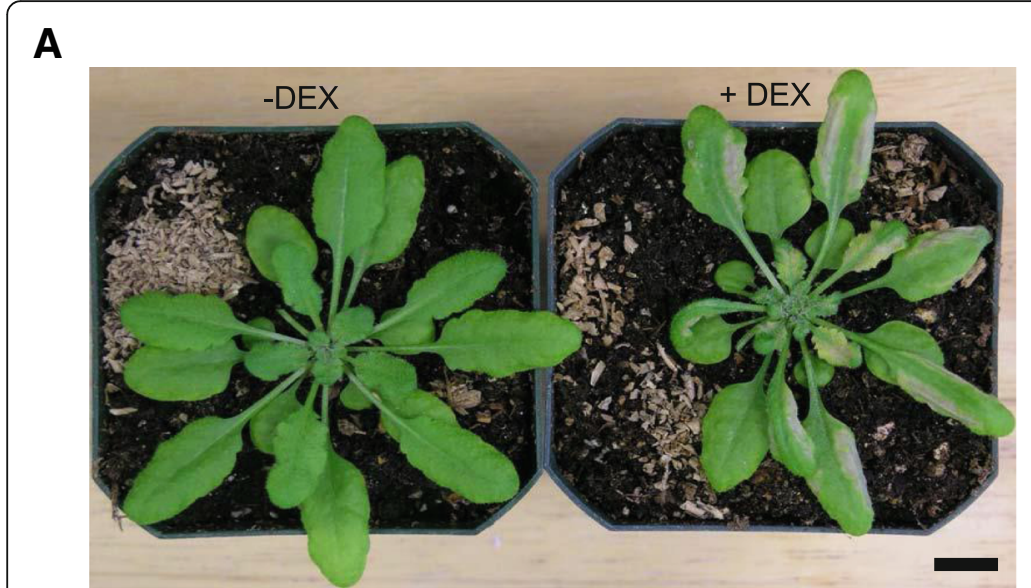

B
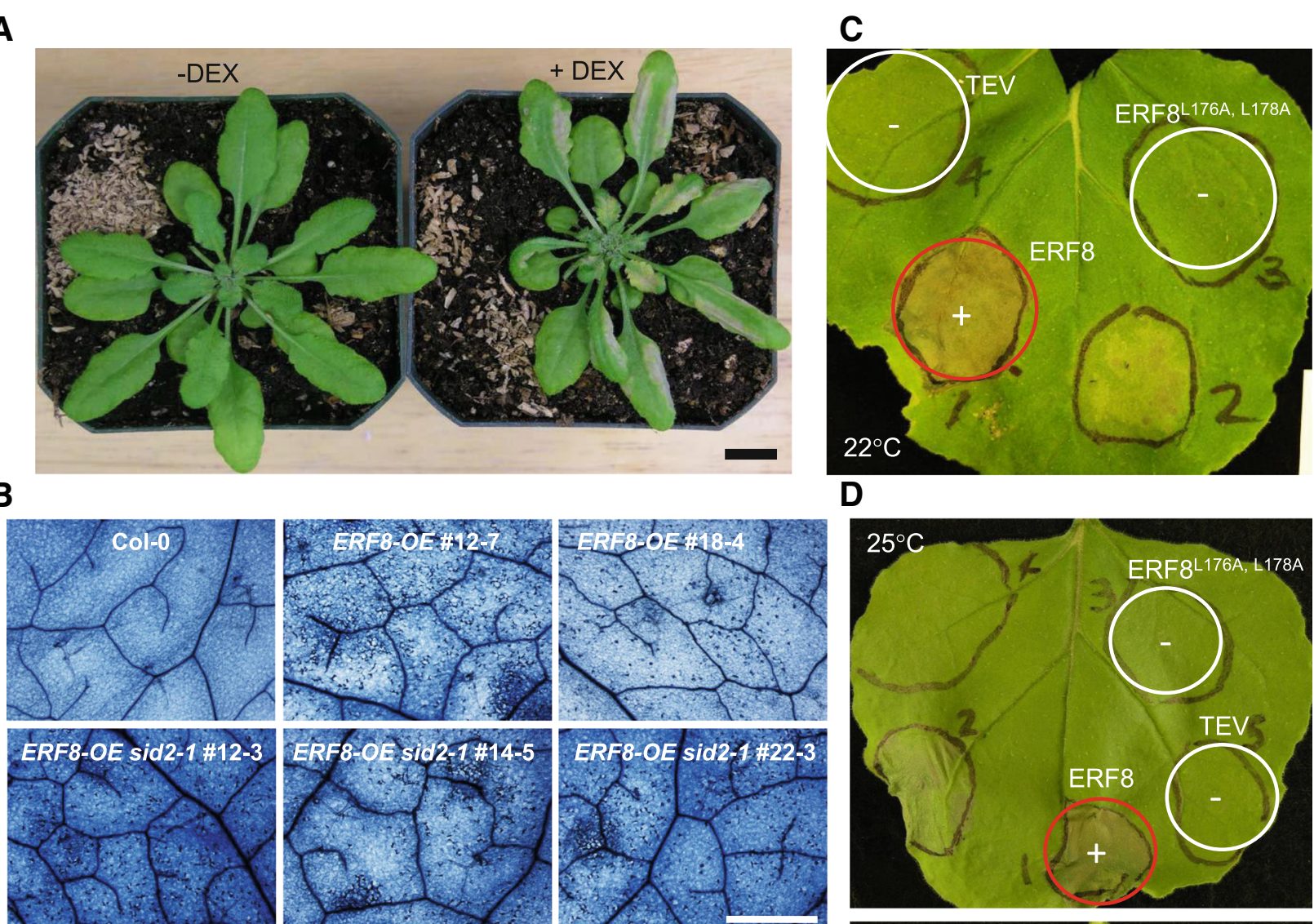

\section{D}

E
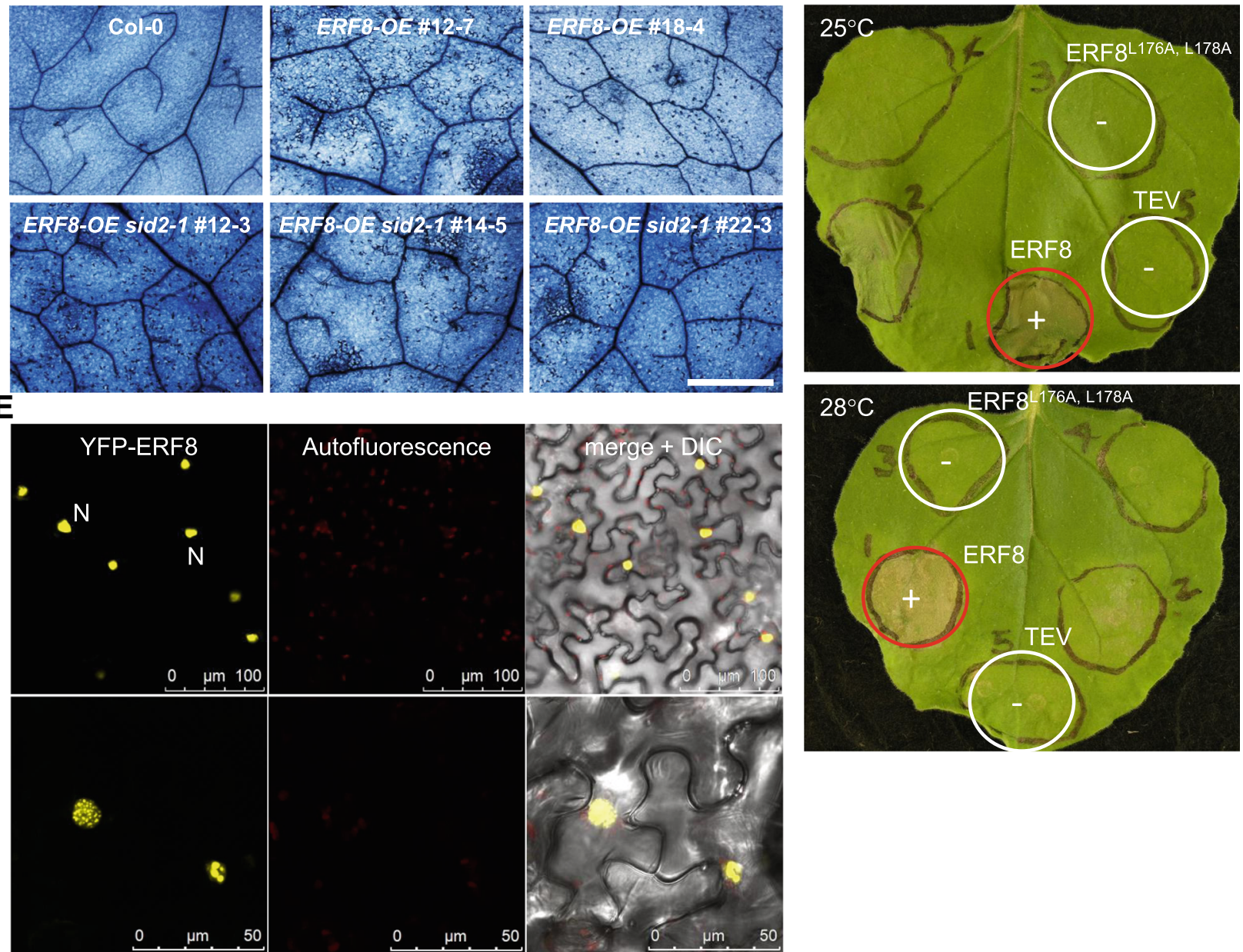

Fig. 2 Over-expression of ERF8 triggers programmed cell death (PCD). (a) DEX-inducible overexpression of ERF8 triggered cell death in transgenic Arabidopsis at $48 \mathrm{~h}$ after DEX treatment. Scale bar $=1 \mathrm{~cm}$ (b) DEX-inducible expression of ERF8 in Col-0 and sid2-1 background led to PCD in Arabidopsis. Leaves from Col-0 and various DEX-inducible ERF8-OE lines were sprayed with $30 \mu \mathrm{M}$ DEX and stained with trypan blue solution.

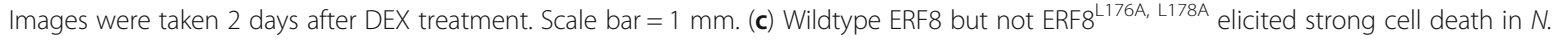
benthamiana. Photo taken 6 days post inoculation (dpi) $(+/$ red circle $=$ cell death, $-/$ white circle $=$ no cell death). (d) ERF8 overexpression induced cell death in $\mathrm{N}$. benthamiana at both $25^{\circ} \mathrm{C}$ and $28^{\circ} \mathrm{C} 3 \mathrm{dpi}$. (e), Transient expression of YFP-tagged ERF8 in N. benthamiana localizes to the nuclei (example nucleus labeled N). Scale bar top $=100 \mu \mathrm{m}$, bottom $=50 \mu \mathrm{m}$ 
cross-pollinated with the salicylic acid induction deficient 2 (sid2-1) mutant. Interestingly, ERF8-induced PCD occurred to a similar degree in sid2-1 as in Col-0 wildtype background plants (Fig. 2b), positioning ERF8 downstream or independent of SA biosynthesis. To corroborate this finding, we next tested the temperature sensitivity of ERF8-induced cell death. Previous studies have shown elevated temperature can supress the development of resistance $(R)$ gene-mediated HR [51], and many SA-dependent autoimmune mutants such as suppressor of npr1-1, constitutive 1 (snc1), suppressor of salicylic acid insensitive4 (ssi4), and constitutive expresser of PR genes 22 (cpr22) showed suppression of immune responses including HR-like spontaneous cell death under modestly elevated temperature (i.e. $28{ }^{\circ} \mathrm{C}$ ) [51], indicative of a connection between temperature and HR cell death. ERF8-induced cell death in $N$. benthamiana, however, was unaffected by elevated temperature $\left(28{ }^{\circ} \mathrm{C}\right)$ (Fig. $\left.2 \mathrm{~d}\right)$, corroborating that ERF8 likely acts downstream or independent from SA accumulation.

\section{The EAR motif is required for ERF8-induced cell death}

Ogata et al. [52] reported that transient expression of several EAR motif-containing group VIII ERFs including ERF8 induced cell death in Nicotiana tabacum. The C-terminal
EAR motif has been shown to be crucial for their transcriptional suppressor function [35, 53]. Given the presence of this EAR motif in ERF8, we set out to determine whether the transcriptional repressor activity of ERF8 is required for its function in promoting cell death. When ERF8 was transiently expressed in $N$. benthamiana as a yellow fluorescent protein (YFP)-fusion, we observed clear signals within nuclei, as expected for a transcriptional repressor (Fig. 2e, top). Higher magnification images revealed that ERF8 is not localized evenly in the nucleus but rather in discreet nuclear bodies (Fig. 2f, bottom). A similar pattern has been reported previously for ERF4 and TCP14 TCP (TEOSINTE BRANCHED1, CYCLOIDEA, PROLIFERATING CELL FACTORS 1 and 2) and it has been suggested that these are sites of protein inactivation and degradation $[54,55]$.

A double leucine to alanine mutation within the EAR motif (L/FDLNL/F(x)P [56, 57], was introduced to disrupt the function of the EAR motif (ERF8 ${ }^{\mathrm{L} 176 \mathrm{~A} / \mathrm{L} 178 \mathrm{~A}}$ ) (Fig. 3a). Although the L176A/L178A mutation did not affect the nuclear localization of ERF8-YFP (Additional file 2a), it abolished the ability of HA-tagged ERF8 to induce cell death (Fig. 2c, d). Western blotting confirmed that ERF8 ${ }^{\mathrm{L} 176 \mathrm{~A} / \mathrm{L} 178 \mathrm{~A}}$ expression was not reduced compared to wild type ERF8 (Additional file 2B), and that ERF8 $8^{\mathrm{L} 176 \mathrm{~A} /}$ L178A ultimately accumulated to higher levels than wildtype

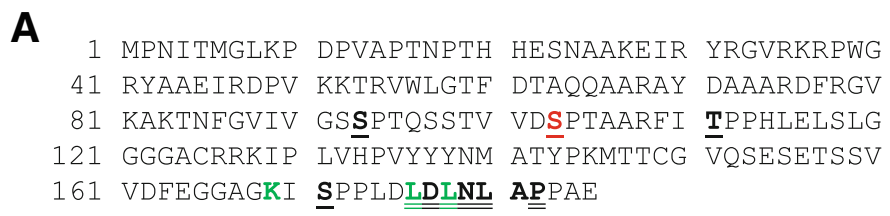

A

1 MPNITMGLKP DPVAPTNPTH HESNAAKEIR YRGVRKRPWG

41 RYAAEIRDPV KKTRVWLGTF DTAQQAARAY DAAARDFRGV

81 KAKTNFGVIV GSSPTQSSTV VDSPTAARFI TPPHLELSLG

121 GGGACRRKIP LVḦPVYYYNM ATȲPKMTTCG V̄QSESETSSV

161 VDFEGGAGKI SPPLDLDLNL APPAE

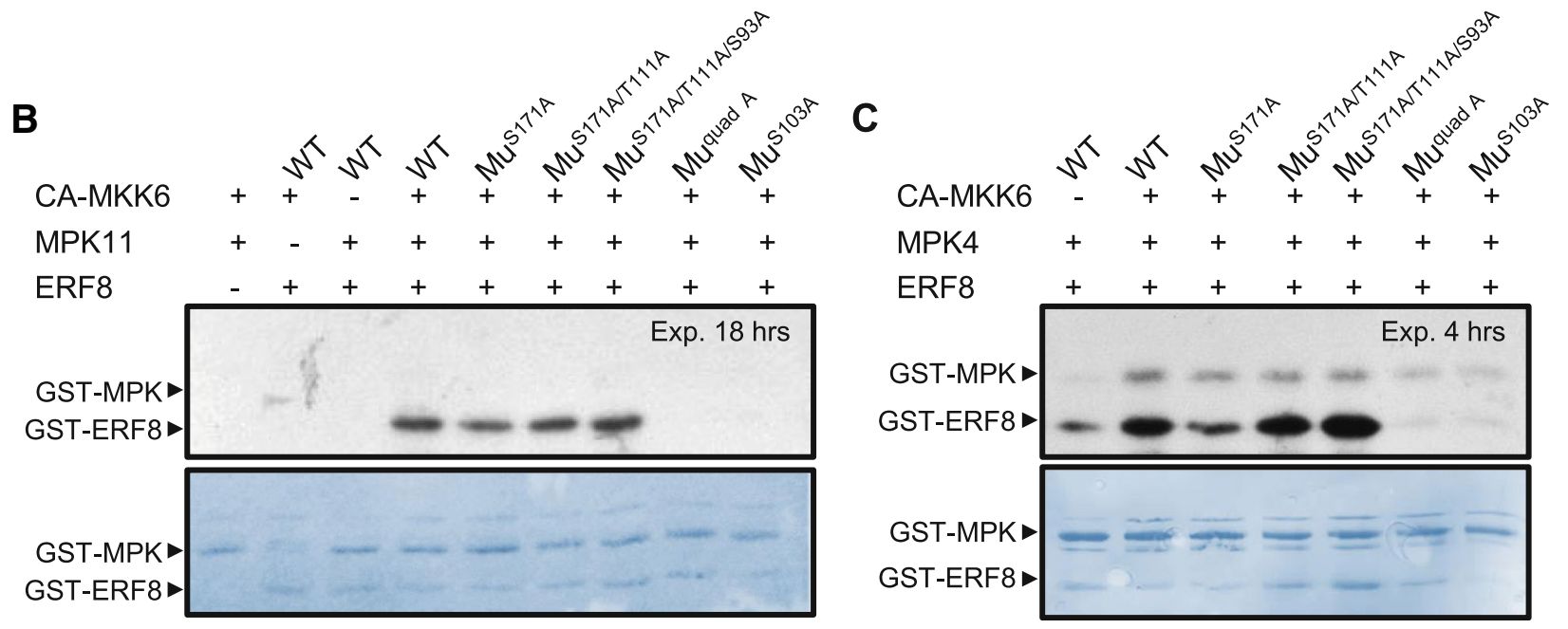

Fig. 3 In vitro phosphorylation of ERF8 by MPKs. (a) Amino acid sequence of ERF8. Bold and underlined are the 4 putative phosphorylation sites (S93, S103, T111, S171), double-underlined is the amphiphilic repression (EAR) motif. Green residues are the putative kinase docking site (Hamel et al. 2011). (b, c) Autoradiographs (top panel) and Coomassie R-250 stained nitrocellulose (bottom panel) are shown. All proteins used were GSTtagged. In reactions containing MPK11 (b) or MPK4 (c) and GST-ERF8; the presence of WT or mutant (Mu) protein is indicated above the image. Four potential phosphorylation sites were changed to alanine via site-directed mutagenesis: S171A, T111A, S103A, and S93A (quad A = quadruple mutant). CA-MKK6 is a constitutive active version of MAP kinase kinase 6, which phosphorylates MPK4 and MPK11 
ERF8 due to the onset of cell death induced by the latter. Interestingly, it had been reported that the EAR motif of the poplar transcriptional repressor, PtiZFP1, partially overlaps with a bipartite MAP kinase docking site, (R/ $\mathrm{K})_{\mathrm{n}} \mathrm{X}_{\mathrm{n}}(\mathrm{LXL})$, which is also found in the $\mathrm{C}$ terminus of group VIIIa ERFs [58]. To distinguish whether transcription suppression through the EAR motif or the potential kinase docking/interacting function of ERF8 is important for cell death induction, the ability for ERF8 and ERF8 ${ }^{\mathrm{L} 176 \mathrm{~A} / \mathrm{L} 178 \mathrm{~A}}$ to interact with MAP kinases was examined. For this analysis, MPK11 was used, as it had previously been identified as an ERF8 interacting protein in yeast two-hybrid $(\mathrm{Y} 2 \mathrm{H})$ assays (Additional file $3 \mathrm{~A}$ ). We were able to validate this interaction between ERF8 and MPK11 as well as the related kinase MPK4 in planta using bimolecular fluorescence complementation (BiFC) assays in $N$. benthamiana (Additional file 3B). Both ERF8 and ERF8 ${ }^{\mathrm{L} 176 \mathrm{~A} / \mathrm{L} 178 \mathrm{~A}}$ clearly interacted with MPK4 and MPK11 in the nucleus, indicating that the L176A/L178A double mutation specifically disrupted the EAR motif and not the putative MPK docking site. Thus, transcription suppression activity is crucial for ERF8-induced cell death.

\section{MPK4 and 11 phosphorylate ERF8}

Given the in planta interactions between ERF8 and MPK4 or MPK11, we tested the ability of these MPKs to directly phosphorylate ERF8 in vitro using recombinantly-expressed GST-fusion proteins. GST-tagged MPK4 or MPK11 were both able to phosphorylate GST-ERF8 in ${ }^{32} \mathrm{P}-\gamma$-ATP kinase assays in the presence of a constitutively-active MAP kinase kinase (MKK), CA-MKK6 [59] (Fig. 3b, c). Four potential MPK phosphorylation sites, Ser93, Ser103, Thr111 and Ser171 (Fig. 3a), were predicted within ERF8 in silico using PhosPhAt [60]. Single, double, triple and quadruple phospho-dead (Ser/Thr to Ala) mutants were generated using site-directed mutagenesis and tested for phosphorylation by MPKs in vitro. The ERF8 ${ }^{\mathrm{S} 171 \mathrm{~A} / \mathrm{T} 111 \mathrm{~A} / \mathrm{S} 93 \mathrm{~A}}$ triple site mutant and other mutant variants with Ser103 unchanged were phosphorylated identically from wildtype ERF8 (Fig. 3). However, both the quadruple mutant (ERF8 $8^{\text {S171A/T111A/ }}$ S93A/S103A $=\mathrm{ERF}^{\text {quad } \mathrm{A}}$ ) or the $\mathrm{ERF} 8^{\mathrm{S} 103 \mathrm{~A}}$ single mutant were no longer phosphorylated by either MPK4 or MPK11 (Fig. 3). These results indicate Ser103 is the predominant ERF8 phosphorylation site by these MPKs. This finding was further validated by Liquid Chromatography-Mass Spectrometry (LC-MS/MS) phosphopeptide analysis as the most abundant ERF8 phosphopeptides identified following in vitro phosphorylation by MPK4 or MPK11 contain Ser103, with both 1 and $3 \mathrm{~h}$ kinase reactions (Table 1 ). In addition, mutating Ser103 to alanine or aspartic acid did not affect the in vitro phosphorylation of other potential phosphorylation residues of ERF8 (Additional file 4), indicating that Ser103 phosphorylation is likely not required for subsequent phosphorylation of additional residue(s).

\section{Mutation of Ser103 alone is not sufficient to Alter ERF8- induced cell death}

To investigate the effect of ERF8 phosphorylation on cell death induction, the phosphomimetic $\left(\mathrm{ERF}^{\mathrm{S} 103 \mathrm{D}}\right)$ and phospho-dead (ERF8 ${ }^{\mathrm{S} 103 \mathrm{~A}}$ ) variants were transiently expressed in $N$. benthamiana. Neither mutation affected the localization of ERF8 to the nucleus (Fig. 4a), while expression of $\mathrm{ERF}^{\mathrm{S103D}}$ or $\mathrm{ERF} 8^{\mathrm{S103A}}$ each induced cell death in a manner similar to wildtype ERF8 (Fig. 4b, c). However, when all 4 phosphorylation residues, Ser93, Ser103, Thr111 and Ser171 were mutated to either alanine or aspartic acid (ERF8 quad A, ERF8 quad D), cell death was delayed and weaker than that induced by wildtype ERF8 (Fig. 4b, c). Western Blot indicated that both quadruple mutant protein levels were lower than wildtype (Additional file 5A), while RT-PCR analysis revealed that the mRNA levels of the wildtype and mutant versions of ERF8 were comparable (Additional file $5 \mathrm{~B}$ ), suggesting that protein stability is affected in the quadruple mutants.

It was previously reported that flg22, a PAMP derived from bacterial flagellin, triggers MPK4-dependent phosphorylation of the EAR-motif possessing transcriptional repressor ARABIDOPSIS SH4-RELATED 3 (ASR3), which fine tunes defense-related transcriptional responses [61]. Since MPK4 and MPK11 are activated upon perception of flg22, we tested the phosphorylation status of ERF8 after flg22 treatment. ERF8 expressed from Arabidopsis protoplasts following flg22 or ABA treatment were examined for a mobility shift, indicative of phosphorylation. As shown in Additional file 6 we did not observe a visible mobility shift in the molecular weight of ERF8 after flg22 or ABA treatment. This observation may be due to the low number of putative MPK-phosphorylated sites on ERF8, which are likely insufficient to induce a detectable change in electrophoretic mobility.

\section{ERF8 overexpression leads to differential expression of genes related to ABA signaling, cell death regulation and immunity}

Our data suggest that transcriptional suppression of target genes by ERF8 is linked to its ability to induce PCD. To examine the downstream targets and signal transduction of ERF8, genome wide transcriptome analysis was performed by RNA-Seq using DEX-inducible ERF8-OE transgenic Arabidopsis plants. Following $8 \mathrm{~h}$ of DEX treatment, plant tissue was harvested for RNA extraction and processed for next generation sequencing. A large number of genes exhibited differential expression in the DEX treated ERF8-OE compared to the empty vector control samples. Eleven thousand seven hundred twenty-one genes showed a minimal of 2 fold change in its expression with 5886 genes that were up-regulated and 5835 genes that were down-regulated (Additional file 7). Genes upregulated by ERF8 over-expression were enriched in biological processes (Gene Ontology (GO) terms) relevant for plant immunity, 
Table 1 Mass spectrometry of MPK4 or MPK11 phosphorylated ERF8

\begin{tabular}{|c|c|c|c|c|c|c|c|c|c|c|}
\hline \multirow{3}{*}{$\begin{array}{l}\text { mutation } \\
\text { site }\end{array}$} & \multirow[t]{3}{*}{ a.a. } & \multicolumn{3}{|c|}{ MPK11/CAKK6 3 h rxn } & \multicolumn{3}{|c|}{ MPK11/CAKK6 1 h rxn } & \multicolumn{3}{|c|}{ MPK4/CAKK6 3 h rxn } \\
\hline & & total spectra & p-spectra & $\% p$ & total spectra & p-spectra & $\% p$ & total spectra & p-spectra & $\% p$ \\
\hline & & 805 (89\%) & $41^{\mathrm{a}}$ & 5.1 & $176(84 \%)$ & $10^{\mathrm{b}}$ & 5.7 & $223(84) \%$ & $30^{c}$ & 13.5 \\
\hline \multirow[t]{3}{*}{1} & Thr69 & 102 & 0 & - & 22 & 0 & - & 31 & 1 & 13.5 \\
\hline & Ser93 & 141 & 3 & 2.1 & 31 & 1 & 3.2 & 46 & 0 & 3.2 \\
\hline & Ser97/98 & 143 & 1 & 0.7 & 32 & 1 & 3.1 & 47 & 6 & - \\
\hline 2 & Ser103 & 143 & 27 & 18.9 & 31 & 5 & 16.1 & 44 & 24 & 12.8 \\
\hline \multirow[t]{6}{*}{3} & Thr111 & 112 & 9 & 9 & 14 & 0 & - & 11 & 0 & 54.5 \\
\hline & Ser118 & 112 & 1 & 0.9 & 14 & 0 & - & 11 & 0 & - \\
\hline & Thr142 & 50 & 0 & - & 20 & 0 & - & 19 & 1 & 5.3 \\
\hline & Thr147/148 & 85 & 1 & 1.2 & 33 & $1(+2)$ & 3 & 34 & 1 & $2.9+$ \\
\hline & Ser153 & 99 & 0 & - & $7(+31)$ & 2 & 5.3 & 40 & 2 & 5 \\
\hline & Ser155 & 102 & 0 & - & $6(+33)$ & 0 & - & 43 & 1 & 2.3 \\
\hline 4 & Ser171 & 5 & 0 & - & $0(+9)$ & 0 & - & $0(+19)$ & 0 & - \\
\hline
\end{tabular}

${ }^{\mathrm{a}}$ One spectra was phosphorylated at two sites

${ }^{b}$ One spectra was phosphorylated at three sites

'Six spectra were phosphorylated at two sites

Summary of data obtained from LC-MS/MS analysis of GST-ERF8 protein after in vitro phosphorylation by GST-MPK4 or GST-MPK11. GST-ERF8 protein was excised

following separation by SDS-PAGE and staining with Coomassie R-250. Numbers indicate the total number of peptide spectra observed for each site, as well as

the total phosphorylated peptide spectra observed for those sites. Peptides identified with $<90 \%$ confidence were excluded from analysis, while ( $+n$ ) indicates

the presence of additional lower probability spectra in some cases. Total percentage sequence coverage of ERF8 is indicated in parentheses for each reaction

including systemic acquired resistance and SA-mediated signaling pathways, cell death and HR-related, defense response. On the other hand, GO terms for down-regulated genes included metabolic pathways, photosynthesis, and glucosinolate biosynthesis (Additional file 8).

As expected for ERF8 being a repressor of ABA responses, the ABA marker RD29A and a number of direct ABA target genes were down-regulated (Table 2). Additionally, of 169 genes that are directly up-regulated by ABA [42], 61 were down-regulated after ERF8 over-expression (Additional file 9). These genes include the biosynthesis genes $A B A 1$ and NCED3, the PP2C AHG3, SnRK3.14, and the transcription factors $A B F 3, R G L 3, N A C 18, N A C 72$ (RD26), MYB77, CIR1, and At-HB12, all of which were connected to ABA-related processes [42]. However interestingly, some ABA-marker genes like RESPONSIVE TO ABA 18 (RAB18), RESPONSIVE TO DESICCATION29B $(R D 29 B)$ and KIN1 were significantly up-regulated, as were the biosynthesis genes, NINE-CIS-EPOXYCAROTENOID DIOXYGENASE5 (NCED5) and ABSCISIC ALDEHYDE OXIDASE3 (AAO3). The ABA receptors PYL6, PYL4 and PYL1 as well as SnRK3.15 were also upregulated (Table 2), while the expression of the strongly ABA-inducible PP2Cs HIGHLY ABA-INDUCED PP2C GENE 1 (HAII) and ABA INSENSITIVE1 (ABI1) $[12,42]$ did not change. This type of discrepancy in ABA-related gene expression upon cell death induction has also been observed in the SA-related autoimmunity mutants, cpr 22 and ssi4 [12, 15], corroborating a role of ERF8 in ABA-SA crosstalk.

Although ERF8-induced cell death was not dependent on SA biosynthesis (Fig. 2b), well characterized SA-mediated pathogen defense-related genes including NON EXPRESSOR OF PATHOGENESIS-RELATED GENES 1 (NPR1), PHYTOALEXIN DEFICIENT4 (PAD4), ENHANCED DISEASE SUSCEPTIBILITY 1 (EDS1), RPM1-INTERACTING4 (RIN4), $P R 1, P R 5$, as well as the SA biosynthesis gene SID2 were significantly induced (Table 2). The up-regulation of genes involved in SA biosynthesis and signal transduction could be attributed by the activation of the SA positive feedback loop [62, 63], in accordance with our hypothesis that ERF8 acts downstream of SA accumulation. Furthermore, pathogen defense-related MAP kinase cascade components were induced. These include $M P K 3,4,6$ and 11, their upstream MKKs as well as their downstream targets WRKY DNA BINDING PROTEIN 33 (WRKY33), ERF104, ACC SYNTHASE 2 (ACS2) and ACS6 that mediate transcriptional changes of defense-related genes upon pathogen invasion [64-67]. Interestingly, MPK11 was up-regulated more than 200 -fold. In contrast to the upregulation of SA signaling, the majority of ethylene-associated genes including the marker genes PDF1.2 and CHI-B did not show significant transcriptional changes even though the ethylene biosynthesis genes ACC synthase (ACS) 7, ACS6 and ACS2 were induced (Table 2). Several class IX $E R F$ genes, $E R F 1, E R F 2$, and $E R F 6$, which have been implicated in immunity [29-32], were also up-regulated, while most other class VIII EAR repressor ERFS showed no significant expression changes. However, ERF8's closest paralog, ERF4, was strongly down-regulated (29 fold), indicating transcriptional feedback regulation. JA-related marker genes displayed either no change (Myc2, LOX2) or were down-regulated (VSP2, AOS). This could be due to the up-regulation of SA signaling at the $8 \mathrm{~h}$ time point. 
A

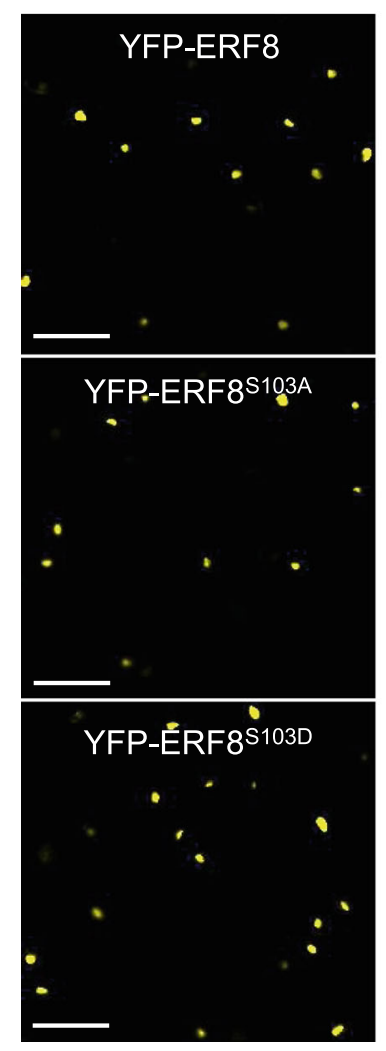

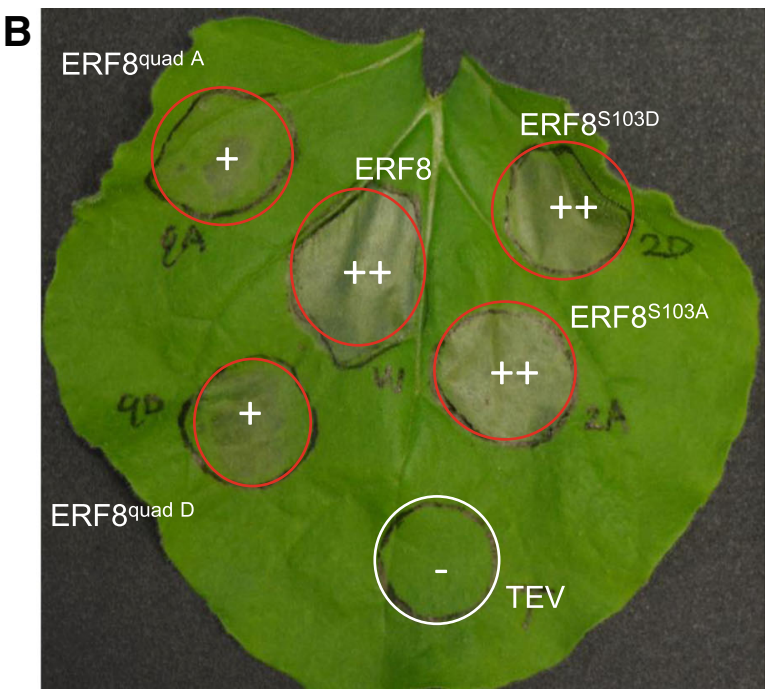

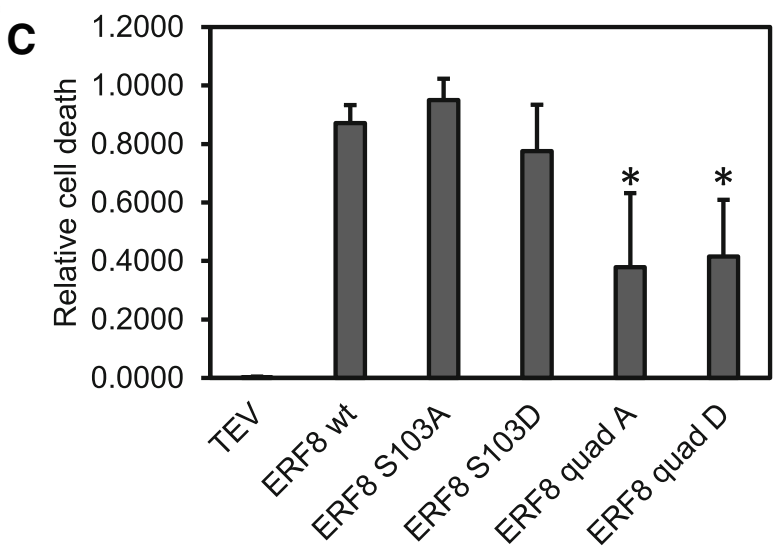

Construct infiltrated

Fig. 4 Mutation of all four phosphorylation sites weakens ERF8-induced cell death. (a) The nuclear localization of YFP-tagged ERF8 is not altered in the S103A and S103A mutants. Shown is transient expression of ERF8 in N. benthamiana 1 dpi. Scale bar $=50 \mu m$. (b) Cell death triggered by ERF8 (W), ERF8 ${ }^{\text {S103A }}$, ERF8 ${ }^{\text {S103D }}$, ERF8 ${ }^{\text {quad A }}$ and ERF8 ${ }^{\text {quad D }}$ at 4 dpi. ++: strong cell death, +: weak/delayed cell death, -: no cell death. (c) Photos of leaves infiltrated with ERF8 variants at 4 dpi were analyzed for cell death severity. The fraction of cell death to healthy leaf tissue from each image was quantified using the ImageJ macro disease image-based quantification (PIDIQ) assay (LaFlamme et al., 2016). Shown are the mean \pm $\mathrm{SD}(n=3)$. Asterisks indicate statistical significance from ERF8 wt (student's t test; $p<0.01)$

As expected, many cell death-related genes were differentially expressed. These include genes encoding for positive and negative regulators of cell death, as well as genes that elicit PCD when they are mis-regulated. For example, the expression of both type I and type II metacaspases $(M C 2-8)$ [68], which are thought to be positive regulators of PCD [69], increased by 2.2- to 378-fold (Table 2). Furthermore, a group of genes that negatively regulate HR-like PCD, including ACCELERATED CELL DEATH11 (ACD11), LESION STIMULATING DISEASE RESISTANCE RESPONSE1 (LSD1), DEFENSE, NO $D E A T H 1$ and 2 (DND1, DND2) [70-72], were down regulated (Table 2). Taken together, the transcriptomic changes associated with ERF8 supports its role as a positive regulator of $\mathrm{PCD}$ and suggests its potential role in pathogen defense.

\section{ERF8 positively regulates bacterial immunity}

Given the results of our cell death assays and genome-wide transcriptional analyses, we investigated whether ERF8 plays a role in plant immunity. ERF8-OE or erf8-1 plants were infected with various strains of the hemi-biotrophic bacterial pathogen, $P$. syringae. As shown in Fig. 5, DEX-treated ERF8-OE Arabidopsis lines displayed increased resistance against the virulent strain, $P$. syringae $\mathrm{pv}$. maculicola ES4326 (Psm ES4326) compared to control plants, suggesting a positive role of ERF8 in pathogen resistance (Fig. 5a). Supporting this observation, erf8-1 plants showed enhanced susceptibility compared to the corresponding wildtype, Ws-2 against Psm ES4326 (Fig. 5b). Interestingly, erf8-1 plants showed more growth of avirulent P. syringae pv. tomato (Pst) DC3000 carrying AvrRps4 (Fig. $5 c$ ) whereas no alteration in pathogen growth was 
Table 2 Selected differentially regulated genes in ERF8-OE transgenic Arabidopsis plants $8 \mathrm{~h}$ after DEX treatment

\begin{tabular}{|c|c|c|c|c|}
\hline Process & Name & AGl & Fold Change & $p$-value \\
\hline \multirow{7}{*}{$\begin{array}{l}\text { Salicylic acid } \\
\text { signaling }\end{array}$} & NPR1 & AT1G64280 & +4.2 & $5.13 \mathrm{E}-038$ \\
\hline & $P R 1$ & AT2G14610 & +18.3 & 2.49E-009 \\
\hline & PR5 & AT1G75040 & +45.5 & $1.98 \mathrm{E}-161$ \\
\hline & ICS1/SID2 & AT1G74710 & +873.7 & 1.34E-238 \\
\hline & EDS1 & AT3G48090 & +26.1 & 4.50E-165 \\
\hline & PAD4 & AT3G52430 & +105.8 & $3.16 \mathrm{E}-175$ \\
\hline & RIN4 & AT2G17660 & +18.2 & 0.017913 \\
\hline \multirow{11}{*}{$\begin{array}{l}\text { MAP kinase } \\
\text { signaling } \\
\text { in defense }\end{array}$} & MEKK1 & AT4G08500 & +4.9 & 7.27E-040 \\
\hline & MKK4 & AT1G51660 & +17.4 & 1.13E-099 \\
\hline & MKK5 & AT3G21220 & +9.4 & 7.46E-081 \\
\hline & MEK1/MKK1 & AT4G26070 & +5 & 4.26E-035 \\
\hline & MKK2 & AT4G29810 & +6.2 & 3.07E-070 \\
\hline & MPK4 & AT4G01370 & +4.9 & 5.73E-049 \\
\hline & MPK11 & AT1G01560 & +214.5 & $1.98 \mathrm{E}-166$ \\
\hline & MPK3 & AT3G45640 & +16.1 & 8.97E-069 \\
\hline & MPK6 & AT2G43790 & +3.5 & $8.14 \mathrm{E}-031$ \\
\hline & WRKYY33 & AT2G38470 & +23.1 & 5.04E-017 \\
\hline & ERF104 & AT5G61600 & +4.6 & 2.21E-006 \\
\hline \multirow{12}{*}{$\begin{array}{l}\text { Cell death- } \\
\text { related genes }\end{array}$} & Bax inhibitor 1 & AT5G47120 & +13.7 & 2.12E-113 \\
\hline & Metacaspase 2 & AT4G25110 & +33.7 & 1.56E-100 \\
\hline & Metacaspase 5 & AT1G79330 & +66.8 & 2.79E-006 \\
\hline & Metacaspase 6 & AT1G79320 & +278.6 & 1.83E-021 \\
\hline & Metacaspase 7 & AT1G79310 & +11.2 & 7.43E-007 \\
\hline & Metacaspase 8 & AT1G16420 & +227.9 & $6.34 \mathrm{E}-128$ \\
\hline & $B A G 2$ & AT5G62100 & +10.2 & $5.25 \mathrm{E}-034$ \\
\hline & BAG6 & AT2G46240 & +2.4 & 5.83E-013 \\
\hline & $A C D 11$ & AT2G34690 & -3.0 & $9.60 \mathrm{E}-023$ \\
\hline & LSD1 & AT1G62830 & -2.3 & $9.75 \mathrm{E}-008$ \\
\hline & DND1 & AT5G15410 & -55.3 & $1.51 \mathrm{E}-155$ \\
\hline & DND2 & AT5G54250 & -24.4 & $9.10 \mathrm{E}-103$ \\
\hline \multirow{4}{*}{$\begin{array}{l}\text { ABA signaling: } \\
\text { ABA marker } \\
\text { genes }\end{array}$} & RD29A & AT5G52310 & -5.2 & 1.78E-015 \\
\hline & $R D 29 B$ & AT5G52300 & +5.9 & 2.20E-007 \\
\hline & $R A B 18$ & AT1G43890 & +3.3 & 1.26E-029 \\
\hline & KIN1 & AT1G14370 & +3.3 & $9.78 \mathrm{E}-026$ \\
\hline \multirow[t]{3}{*}{ ABA receptors } & PYL1 & AT5G46790 & +3.2 & 2.85E-025 \\
\hline & PYL4 & AT2G38310 & +5.9 & 2.44E-025 \\
\hline & PYL6 & AT2G40330 & +41.5 & $3.58 \mathrm{E}-067$ \\
\hline \multirow[t]{2}{*}{ SnRK kinases } & SnRK3.15 & AT5G01820 & +2.3 & 1.57E-013 \\
\hline & SnRK3.14 & At4g30960 & -7.4 & 7.44E-060 \\
\hline \multirow[t]{4}{*}{ PP2Cs } & $A B / 1$ & AT4g26080 & NS & - \\
\hline & HAB1 & At1g72770 & NS & - \\
\hline & HAl1 & AT5g59220 & NS & - \\
\hline & AHG3 & AT3G11410 & -4.3 & 2.06E-031 \\
\hline
\end{tabular}

Table 2 Selected differentially regulated genes in ERF8-OE transgenic Arabidopsis plants $8 \mathrm{~h}$ after DEX treatment (Continued)

\begin{tabular}{|c|c|c|c|c|}
\hline Process & Name & AGl & Fold Change & $p$-value \\
\hline \multirow{4}{*}{$\begin{array}{l}\text { ABA } \\
\text { biosynthesis }\end{array}$} & $A B A 1$ & At5g67030 & -5.9 & $5.56 \mathrm{E}-024$ \\
\hline & AAO3 & AT2G27150 & +3.0 & $5.34 \mathrm{E}-021$ \\
\hline & NCED3 & At3g14440 & -3.6 & $3.90 \mathrm{E}-016$ \\
\hline & NCED5 & AT1G30100 & +8.7 & 2.65E-015 \\
\hline \multirow{7}{*}{$\begin{array}{l}\text { Transcription } \\
\text { factors }\end{array}$} & $A B F 3$ & AT4g27410 & -17.3 & $3.18 \mathrm{E}-007$ \\
\hline & CIR1 & At5g37260 & -19.7 & $5.69 \mathrm{E}-044$ \\
\hline & At-HB12 & At3g61890 & -28.8 & $1.95 \mathrm{E}-018$ \\
\hline & RGL3 & AT5G17490 & -4.7 & 1.00E-006 \\
\hline & NAC72 (RD26) & At4g27410 & -3.0 & $3.18 \mathrm{E}-007$ \\
\hline & NAC18 & At1g52880 & -2.6 & $3.62 \mathrm{E}-008$ \\
\hline & Myb77 & At3g50060 & -2.2 & 0.007121 \\
\hline \multirow{11}{*}{$\begin{array}{l}\text { Ethylene } \\
\text { signaling }\end{array}$} & ACS7 & AT4G26200 & +1297 & $2.73 \mathrm{E}-245$ \\
\hline & ACS2 & AT1G01480 & +4.5 & 0.003495 \\
\hline & ACS6 & AT4G11280 & +5.8 & $1.48 \mathrm{E}-005$ \\
\hline & ERS1 & AT2G40940 & +2.1 & $1.80 \mathrm{E}-012$ \\
\hline & EIN4 & AT3G04580 & +6.6 & $1.14 \mathrm{E}-067$ \\
\hline & EIN3 & AT3G20770 & NS & $5.08 \mathrm{E}-012$ \\
\hline & ERF1 & AT3G23240 & +369.5 & 2.37E-209 \\
\hline & ERF4 & AT3G15210 & -28.8 & $1.36 \mathrm{E}-028$ \\
\hline & ERF8 & AT1G53170 & +127 & 2.07E-278 \\
\hline & PDF1.2 & AT5G44420 & NS & - \\
\hline & $C H I-B$ & AT3g12500 & NS & - \\
\hline
\end{tabular}

Fold change is relative to DEX treated empty vector transgenic plants. NS $=$ no significant change

observed with Pst DC3000 carrying AvrB (Fig. 5d), indicating a role of ERF8 in immunity.

\section{Discussion}

In this study, we investigated a class II ERF transcriptional repressor, ERF8, which induces PCD in two model plant species, A. thaliana and N. benthamiana. Mutation of the conserved transcriptional suppression EAR motif completely abolished the ability of ERF8 to induce cell death, indicating its transcriptional repression activity is essential for cell death induction. These data corroborate previous studies of proposed roles for class II ERFs in cell death induction $[36,52,53]$.

Previous studies have revealed different modes of regulation of ERF transcription factors, including co-transcriptional regulators, miRNA, alternative polyadenylation, phosphorylation and proteasome-mediated degradation $[28,30,31,36$, 73]. ERF8 contains a putative MAP kinase docking site, and in this study we demonstrated two immunity-related kinases, MPK4 and MPK11, interact with and directly phosphorylate ERF8. MPK4 in particular has been studied extensively in the context of plant immunity [43-47]. The $m p k 4$ mutant 

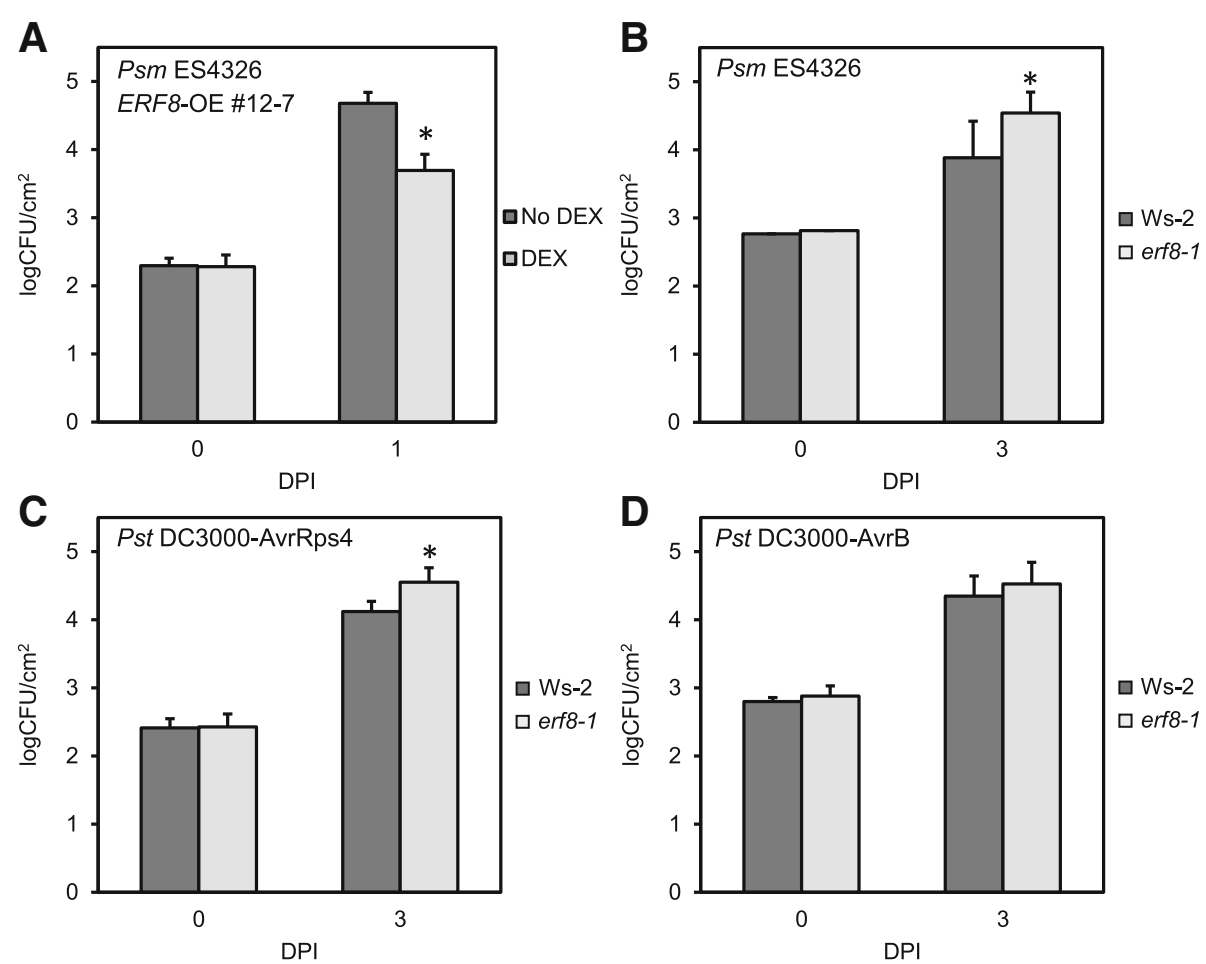

Fig. 5 ERF8 is involved in defense against Pseudomonas syringae. Virulent P.s. pv maculicola $\mathrm{ES}_{4326}\left(P_{s m}\right)$ was pressure infiltrated at an $\mathrm{OD}_{600}$ of 0.0001 into control or DEX-treated ERF8-OE plants (a) or erf8-1 knockdown plants (b). Avirulent Pseudomonas syringae pv. tomato DC3000 (Pst) carrying AvrRps4 (c) or AvrB (d) was pressure infiltrated into wildtype Ws-2 and erf8-1 knockdown plants. In planta bacterial growth was quantified at 1 or 3 days post inoculation (dpi). Asterisks indicate statistical significance (student's t test; $p<0.01$ ). Experiments were conducted twice (C\&D) or 3 times (A\&B) and showed reproducible results ( $n=3$ for $0 \mathrm{dpi}, n=8-10$ for 1 or $3 \mathrm{dpi}$ )

exhibits extreme dwarf phenotypes and autoimmunity including spontaneous PCD [45, 74]. Several MPK4 interactors and/or substrates have been previously identified, including MAP KINASE SUBSTRATE 1 (MKS1), which is required the SA-dependent autoimmunity phenotype of $m p k 4$ [75]. MKS1 phosphorylation by MPK4 occurs following pathogen infection, leading to WRKY33-induced expression of PAD3, which is required for biosynthesis of the antimicrobial phytoalexin, camalexin [65]. Another target of MPK4 is the PROTEIN ASSOCIATED WITH TOPOISOMERASE II (PAT1), a component of the mRNA decapping machinery [76]. PAT1 also interacts with the CC-NB-LRR protein, SUMM2 (SUPPRESSOR OF mkk1 mkk2), mutation of which can partially suppress autoimmune phenotypes of $m p k 4$ [76, 77]. The absence of PAT1 triggers SUMM2-dependent immunity, and based on these findings, it has been proposed that MPK4 positively regulates PTI and also acts as a guardee, suggesting that the loss of MPK4 induces SUMM2-mediated ETI $[76,77]$. Another MPK4 interactor is the transcriptional repressor ARABIDOPSIS SH4-RELATED3 (ASR3), which negatively regulates a large subset of flg22-induced genes. Phosphorylation of ASR3 by MPK4 enhances its DNA binding activity to suppress gene expression [61]. It will be interesting to determine if ERF8 interacts with some of these known targets of MPK4 and functions within the same protein complexes or in an overlapping signal transduction pathway leading to pathogen resistance and $\mathrm{PCD}$ induction.

Given the roles of MPK4 and MPK11 in immunity, we hypothesized that ERF8-induced cell death is regulated by phosphorylation. Our in vitro kinase assays and LC-MS/MS results indicate MPK4 and MPK11 predominantly phosphorylate ERF8 at residue Ser103. Thus, phosphomimetic and phosphoablative variants in this single residue (ERF8 $\left.{ }^{\mathrm{S} 103 \mathrm{D} / \mathrm{A}}\right)$ were generated and overexpressed in $N$. benthamiana, but no significant difference in cell death was observed relative to wildtype ERF8. However, in contrast, when all 4 potential phosphorylation residues Ser93, Ser103, Thr111 and Ser171 were mutated to alanine or aspartic acid, ERF8-induced cell death was reproducibly delayed and weakened. It is likely that the phosphomimetic mutations failed to reproduce changes to ERF8 caused by phosphorylation due to differences in charge and size between an aspartate residue and a phosphate group [78], which suggests phosphorylation by MPK4 an MPK11 positively regulates ERF8 to induce cell death. The sequence coverage in our LC-MS/MS data is low for the 4th potential phosphorylation residue Ser171 (Table 1), presumably due to its proximity to the $\mathrm{C}$-terminal end of the protein, and thus it remains possible that other site(s) along with Ser103 are 
phosphorylated by MPK4 and MPK11 in vivo to regulate cell death. Phosphorylation may stabilize the ERF8 protein level, as the quadruple phosphosite mutants displayed lower protein accumulation in planta, while mRNA levels were unaffected (Additional file 5). The induction or activation of MPK11 and/or MPK4 upon pathogen infection may therefore reduce ERF8 turnover and contribute to PCD formation. Regulation of ERF8 through turnover by the 26S proteasome was previously suggested [36]; it was shown that treatment with the proteasome inhibitor MG132 slowed down protein turnover. Protein turnover of ERF8 (and ERF4) was also slowed down as plants aged and it was suggested that this would contribute to the induction or execution of senescence-associated cell death [36]. Further analysis of the mechanism(s) of ERF8 phospho-regulation is on-going.

As previously shown for other class VII ERFs, including ERF7 and ERF4, ERF8 acts as a negative regulator of ABA responses [39, 42, 54] (Fig. 1). It is believed that ERFs bind to the GCC and DRE elements in promoters and form a repressor complex with co-repressors, such as TOPLESS, histone deacetylase HDA19 and its interactor Sin3 [39, 79].

In this study, ERF8 over-expression led to the down-regulation of 5835 genes. Many of those are probably altered because of secondary effects due to elevated SA levels, but the fact that $36 \%$ of genes that are directly induced by ABA [42] were down-regulated after induction of $E R F 8$ expression strongly suggests that ERF8 is indeed a transcriptional repressor of ABA responses. Interestingly, one of the strongly down-regulated genes was ERF4, the closest paralog of $E R F 8$, indicating cross-regulation between these transcription factors. It had been suggested that both ERF4 and ERF8 co-regulate senescence through their repressor function and over-expression of either gene caused reduced ABA sensitivity [36, 54] (Fig. 1), however, Caarls et al. (2017) [80] showed that ERF8 but not ERF4 regulates PDF1.2 and PR1 gene expression, suggesting distinct roles for these two transcription factors. ERF8 was recently also identified as part of a network of ERF transcription factors (together with ERF6, ERF9, ERF59 and ERF98) that controls osmotic stress [81].

Olvera-Carrillo et al. (2015) [82] previously identified transcriptional profiles differentiating HR-like (biotic stress) cell death from developmental cell death. The ERF8 set overlapped in 27 out of 28 genes that were up-regulated in their biotic stress set, while only 8 of 25 developmental PCD marker genes were up-regulated, 11 did not change and 6 were down-regulated, confirming the immunity-specific nature of ERF8-induced cell death. However, transcriptional changes at our selected time point (8 $\mathrm{h}$ post ERF8 induction) seemed sufficient to trigger extensive secondary transcriptional reprogramming in Arabidopsis. Particularly, the SA biosynthesis gene ICS1 (SID2) was upregulated strongly and thus it likely led to SA-mediated secondary transcriptional changes (a positive amplification loop), making it difficult to identify direct ERF8 target genes. Three hundred genes with a GCC box in their promoter $(-2000$ to +200 ; [83]) were down-regulated and 249 were up-regulated. Similarly more than 200 genes with a DRE element in their promoter were up or down regulated, respectively (Additional file 8). Interestingly, of the 61 genes that are directly up-regulated by ABA but down-regulated in our data set (Additional file 9) $33(54 \%)$ contained a DRE element in their promoter, 3 had a GCC element and 4 contained both GCC and DRE elements. Furthermore, the down-regulated ABA-related genes RD29A, RD26/NAC072 also contain a DRE element, SnRK3.14 a GCC element, and NCED3 and HB12 GCC and DRE elements in their promoters. These could be direct ABA-related targets of ERF8. The down-regulated cell death-related genes, $D N D 1$ and $A C D 11$, also contain DRE elements in their promoters. DND1 has been shown to be a target of Topless-related 1 (TPR1) [72] and topless proteins have been shown to interact with ERF8 [79] raising the possibility that ERF8 and topless proteins may be co-suppressors of $D N D 1$ and potentially other genes from our data set. Further analyses to identify the immediate target(s) of ERF8 will be the key to understanding how this transcriptional repressor integrates $\mathrm{ABA}$ and cell death.

Finally, we demonstrated the functional role of ERF8 in immunity, as overexpression in Arabidopsis increased resistance against Psm ES4326, while erf8-1 plants exhibited enhanced susceptibility to virulent Psm ES4326 as well as Pst DC3000 expressing AvrRps4. Cumulatively, our data demonstrate that ERF8 functions in both ABA signaling and bacterial immunity. The attenuation of resistance to Pst AvrRps4 suggests a link to ETI conferred by TIR-NB-LRR class $R$-genes like $S N C 1$ [72]. Indeed, in a separate study (Cao et al., submitted) we show that ERF8 is targeted by multiple $P$. syringae type III effector proteins, further corroborating an important role of ERF8 in plant immunity. Further study of the ERF8-mediated crosstalk with ABA signaling will be a promising avenue to understand the transcriptional network in abiotic and biotic responses.

\section{Conclusions}

In this study, we revealed that the ABA-inducible transcriptional repressor ERF8 has dual roles in ABA signaling and immunity. ERF8 acts as a negative regulator of ABA signaling as the erfo knockdown line displayed enhanced ABA sensitivity while overexpression lines showed decreased sensitivity. Additionally, over-expression of ERF8 caused SA-independent PCD as well as enhanced pathogen resistance, suggesting a positive role in plant immunity. However, the EAR repressor domain was required for PCD formation and a number of PCD-associated genes were down-regulated in ERF8 overexpression lines, suggesting that ERF8 may down-regulate negative regulators of immunity signaling. Finally, we show that ERF8 is 
phosphorylated by the two immunity-related MAP kinases, MPK4 and MPK11. Ser103 was predominantly phosphorylated in vitro; however mutation of all four putative phosphorylation sites seemed to be necessary to partially suppress ERF8-induced cell death in $N$. benthamiana.

\section{Methods}

\section{Plant growth conditions}

Arabidopsis thaliana and Nicotiana benthamiana seeds were grown in Sunshine Mix (Sun Gro Horticulture Canada) in a growth chamber at $9 \mathrm{~h}$ light and $16 \mathrm{~h}$ dark cycles at $22{ }^{\circ} \mathrm{C}$ and $20{ }^{\circ} \mathrm{C}$ respectively. Light intensity was approximately $130 \mu \mathrm{E} \mathrm{m} \mathrm{m}^{-2} \mathrm{~s}^{-1}$.

\section{Generation of Arabidopsis transgenic plants}

Arabidopsis plants were transformed following the floral dip method using Agrobacterium (strain GV3101) carrying the binary plant expression vector pMAC14 containing a DEX-inducible ERF8-HA-tag construct. BASTA-resistant individuals were selected and leaves from 5 -week-old $\mathrm{T} 1$ transformants were treated with $30 \mu \mathrm{M}$ DEX for 2 days, after which leave samples were frozen in liquid nitrogen and prepared for western blotting to detect protein expression of the transgene. T1 individuals with confirmed transgene expression were carried to the next generation and homozygous T3 transgenic lines were used for experiments. The ERF8 knockdown line FLAG157D10 was obtained from the ABRC stock center.

\section{Germination assays}

Sterilized seeds were plated onto 0.5X Murashige and Skoog (MS) media (pH 5.8; Sigma) supplemented with ABA (Sigma) or dexamethasone (DEX; Bioshop). Germination was scored based on radicle or cotyledon emergence observed under a dissecting microscope.

\section{Cloning and agrobacterium-mediated transient expression in N. Benthamiana}

Wildtype and mutant variants of ERF8, MPK4, and MPK11 were sub-cloned using gateway LR clonase II (Invitrogen) into the binary expression vectors pBWGYn2 or pBWGYc2 (for bimolecular fluorescence complementation, BiFC), pEARLEY201 (for protein expression with a C-terminal HA tag), or pEARLEY104 (with an N-terminal YFP tag for cellular localization analyses). A. tumefaciens (GV2260 or C58C1) were transformed with the constructs and transient assays were conducted as described [84]. Agrobacterium carrying CaMV35S::HC-Pro from tobacco etch virus (TEV) was co-infiltrated with constructs to suppress gene silencing. For $\mathrm{BiFC}$ and co-infiltration experiments, equal volumes of cultures were mixed prior to infiltration. Six week old $N$. benthamiana leaves were infiltrated from the underside using needleless syringes as described previously [84].

\section{Confocal microscopy}

Discs were cored from infiltrated $N$. benthamiana leaf areas and imaged using the Leica TCS SP5 confocal system (Leica Microsystems). Images were acquired with the Argon laser set to 20\%, using excitation at $514 \mathrm{~nm}$ and emission from 525 to $600 \mathrm{~nm}$ for YFP detection. Autofluorescence of chloroplasts was detected by emission between 650 and $700 \mathrm{~nm}$ [36].

\section{Western blotting}

Arabidopsis and $N$. benthamiana tissue was frozen in liquid nitrogen and ground into fine powder. Proteins were extracted in $20 \mathrm{mM}$ TRIS- $\mathrm{HCl}$ pH $8.0,100 \mathrm{mM} \mathrm{NaCl}$, $1 \mathrm{mM}$ DTT and $1.25 \%$ Triton X-100. Samples were centrifuged at $6000 \times g$ for $10 \mathrm{~min}$ at $4{ }^{\circ} \mathrm{C}$ to remove debris. Resulting protein extracts were boiled in 1X SDS loading dye at $90{ }^{\circ} \mathrm{C}$ for $5 \mathrm{~min}$. After Western blotting proteins were detected using $\alpha$-HA antibodies (1:10,000; Roche) and peroxidase-conjugated mouse $\alpha$-rabbit IgG (1:30,000; Cell Signaling). Immuno-reactive bands were detected using the ECL prime western blotting kit (GE Healthcare).

\section{In vitro kinase assays}

ERF8, MPK, and CA-MKK proteins used in kinase assays were expressed as recombinant GST-fusion proteins in $E$. coli BL21 codon plus cells using the pGEX4T3 expression vector. GST-fusion proteins were purified via GSH-agarose chromatography and eluted in $50 \mathrm{mM}$ HEPES, $100 \mathrm{mM}$ $\mathrm{NaCl}, 5 \%$ glycerol, $1 \mathrm{mM}$ DTT, pH 7.5 by addition of $10 \mathrm{mM}$ reduced GSH. Proteins were quantified and stored at $-80{ }^{\circ} \mathrm{C}$ until use. For kinase assays, $1 \mu \mathrm{g}$ of GST-ERF8 (WT or mutant as indicated in figures) was incubated with $0.5 \mu \mathrm{g}$ GST-CA-MKK and $0.5 \mu \mathrm{g}$ GST-MPK in $25 \mathrm{mM}$ Tris-Cl, $10 \mathrm{mM} \quad \mathrm{MgCl}_{2}, 1 \mathrm{mM} \quad \mathrm{Na}_{3} \mathrm{VO}_{4}, 1 \mathrm{mM}$ $\beta$-glycerophosphate, $\mathrm{pH}$ 7.5. Reactions were initiated by addition of ATP (final concentration $100 \mu \mathrm{M}$ ATP $+2 \mu \mathrm{Ci}$ $\left[\gamma^{-}{ }^{32} \mathrm{P}\right]$-ATP). Following incubation at $30^{\circ} \mathrm{C}$ for $2 \mathrm{~h}$ reactions were stopped by addition of $1 \mathrm{X}$ SDS loading dye and heating to $95{ }^{\circ} \mathrm{C}$ for $10 \mathrm{~min}$. Proteins were separated on 15\% SDS-PAGE and transferred to nitrocellulose. Radiolabeled proteins were detected by film exposure for times indicated in figures.

\section{LC-MS/MS}

In vitro kinase assays were performed as described above with the following changes. Assays were conducted with unlabeled ATP, and used $5 \mu \mathrm{g}$ GST-ERF8 protein and $1 \mu \mathrm{g}$ each GST-CA-MKK6 and GST-MPK4 or GST-MPK11 (as indicated in figures). Reactions were incubated for 1 or $3 \mathrm{~h}$ as described in figures. GST-ERF8 protein was excised following separation by SDS-PAGE and staining with Coomassie R-250 and sent for in-gel trypsin digestion and LC-MS/MS phosphopeptide analysis (Mass Spectrometry Facility, SPARC BioCentre). 


\section{Visualization of microscopic cell death by trypan blue staining}

Leaves were submerged in lactophenol-trypan blue solution, heated in boiling water in a fume hood for 3-5 min and stained at room temperature for $2 \mathrm{~h}$. Samples were destained in $50 \%$ chloral hydrate $(w / v)$ overnight, washed and stored in $50 \%$ glycerol before mounting onto glass slides for images analysis and photography.

\section{Quantification of cell death}

Images were pre-processed using Photoshop. Individual infiltration spots were cropped and saved as separate images. Area outside the infiltrated tissue was filled in red to allow infiltrated leave tissue to be distinguished from un-infiltrated leave tissue. The fraction of cell death to healthy leaf tissue from each image was quantified using the ImageJ macro disease image-based quantification (PIDIQ) [85] with the following change in parameters: green area (hue: 50-104; saturation: 151-255; brightness: 0-255); cell death area (hue: 0-255; saturation: 0-150; brightness: 0-255). The average fraction of cell death from at least 3 leaves was depicted in figures.

\section{Protoplast transfection assay}

Protoplast transfection assay was performed as previously described (Li et al., 2015). Briefly, $200 \mu \mathrm{l}$ of Arabidopsis protoplasts at $2 \times 10^{5} \mathrm{cells} / \mathrm{ml}$ were transfected with $40 \mu \mathrm{g}$ plasmids expressing ERF8 or its variants or MKP phosphatase. Twelve hours after transfection, the protoplasts were treated with $100 \mathrm{nM}$ flg22 for $15 \mathrm{~min}$ or $10 \mu \mathrm{M} \mathrm{ABA}$ for 15 or $30 \mathrm{~min}$. For K252a treatment, $1 \mu \mathrm{M} \mathrm{K} 252 \mathrm{a}$ was added to the protoplasts right after transfection. The protoplasts were isolated for Western Blot analysis with anti-HA antibody.

\section{RNA extraction and Illumina mRNA-Seq methods}

Three replicates were used for each genotype (empty vector and ERF8-OE $8 \mathrm{~h}$ after DEX treatment). Each replicate contains 3 leaves pooled from 3 plants that were 4 weeks old. RNA was extracted from plant tissues using the TRIzol reagent following the manufacturer's protocol (Thermo Fisher Scientific, Waltham, MA USA). The RNA was further purified using the PureLink ${ }^{\mathrm{m}} \mathrm{RNA}$ Mini Kit (Thermo Fisher Scientific, Waltham, MA USA). RNA was bound, washed and eluted following the manufacturer's protocol. Eluted RNAs were treated with the Turbo DNA-free ${ }^{\mathrm{mix}}$ kit (Thermo Fisher Scientific, Waltham, MA USA) to remove residual double-stranded DNA following the protocol from the manufacturer. The quality and quantity of the RNAs were assessed using the RNA Nano kit for the Bioanalyzer 2100 (Agilent Technologies, Palo Alto, CA). mRNA was isolated from the total RNA using the Dynabeads ${ }^{\circ}$ mRNA Purification Kit (Thermo Fisher Scientific, Waltham, MA USA) following the recommended protocol. The mRNA was sheared to 300 base size using the Covaris S2 Ultrasonicator (Covaris, Woburn, MA) with the following protocol: duty $=10 \%$; intensity $=5 \%$; cycles per burst $=200$ and time $=35 \mathrm{~s} \mathrm{X} 2$. The sheared mRNA was precipitated overnight and resuspended in 14ul of RNase-free water.

Illumina libraries were prepared using the NEBNext ${ }^{\circ}$ mRNA Library Prep Master Mix set for Illumina kit (New England Biolabs, Ipswich, MA, USA) starting at the first strand cDNA synthesis step and following the recommended protocol. NEB single index barcodes were added for multiplexing purposes. The final library was sequenced on the NextSeq500 sequencer (Illumina, San Diega, CA), according to the manufacturer's instructions, using the 150 cycle Mid Output V2 sequencing kit and generating $150 \times 2$ paired end reads.

\section{RNA-Seq data processing}

RNA-Seq reads were mapped to Arabidopsis gene sequences with the short read mapper novoalign (novocraft.com). The homopolymers and reads with low qualities were filtered by the mapper. The number of reads mapped to each gene were subsequently counted for each sample. The read count data were inputted to the R package edgeR [86] for gene differential expression analysis. Differentially expressed genes were grouped into up-regulated genes and down-regulated genes.

Sequence read numbers ranged from 8.2 to 17.6 million for each ERF8-OE or empty vector (EV) control sample, of which more than $83 \%$ were uniquely mapped to Arabidopsis genes, while only $0.4 \%$ of the reads were mapped to multiple locations. About $0.6 \%$ of the reads were filtered by the aligner due to being homopolymers. Around 14\% of the reads have no match reported, presumably due to low quality. The reproducibility of the samples was assessed with the coefficient of determination for the gene-wise read counts data, which ranged $96-98 \%$ within the same genotype and 36-46\% between different genotypes. Differentially expressed genes were searched for 1) GCC box/motif (TAAGAGCCGCC or AGCCGCC) in promoter region $-2000 \mathrm{bp}$ to $+200 \mathrm{bp}$ and/or 2) $\mathrm{DRE}$ motif (A/GCCGAC) in promoter region -2000 bp to $0 \mathrm{bp}$.

\section{P. Syringae growth assays}

P. syringae strains were inoculated at $\mathrm{OD}_{600} 0.002$ for $P m a$ ES4326, $\mathrm{OD}_{600} 0.001$ for Pst DC3000, or $\mathrm{OD}_{600} 0.002$ for Pst DC3000-AvrRps4 and Pst DC3000-AvrB. To quantify in planta bacterial growth, four disks $\left(1 \mathrm{~cm}^{2}\right)$ per plant were harvested, ground in $10 \mathrm{mM} \mathrm{MgCl}$, and plated on King's broth (KB) with the appropriate antibiotics for colony counting. DEX-inducible transgenic plants were sprayed with $30 \mu \mathrm{M}$ DEX 1 day in advance to induce transgene expression. 


\section{Additional files}

Additional file 1: Figure S1. ERF8 expression in seeds and after DEX treatment. (PPTX $512 \mathrm{~kb}$ )

Additional file 2: Figure S2. Localization and expression of ERF8 wildtype and L176A L178A mutant variant in N. benthamiana. (PPTX 6667 $\mathrm{kb})$

Additional file 3: Figure S3. Interaction of ERF8 and MPK11 in $\mathrm{Y} 2 \mathrm{H}$. (PPTX $1630 \mathrm{~kb}$ )

Additional file 4: Figure S4. Phosphorylation of Ser103 does not affect phosphorylation of other ERF8 residues in vitro. (PPTX $204 \mathrm{~kb}$ )

Additional file 5: Transient expression of ERF8 wt and variants in N. benthamiana. (PPTX $129 \mathrm{~kb}$ )

Additional file 6: Figure S6. Analysis of ERF8 and its phosphorylation status under various conditions. (PPTX $154 \mathrm{~kb}$ )

Additional file 7: Table S7. Differentially regulated genes in ERF8-OX plants $8 \mathrm{~h}$ after DEX treatment. (XLSX $789 \mathrm{~kb}$ )

Additional file 8: Figure S8. Analysis of differentially expressed genes. (PPTX $39 \mathrm{~kb}$ )

Additional file 9: Table S9. Genes up-regulated by ABA and downregulated in ERF8-OX plants. (XLSX $11 \mathrm{~kb}$ )

\section{Abbreviations}

ABA: abscisic acid; BiFC: bimolecular fluorescence complementation; DEX: dexamethasone; EAR: ERF-associated amphiphilic repression (EAR); HR: hypersensitive response; OE: over-expresser; PCD: programmed cell death; Pst: P. syringae pv. tomato; SA: salicylic acid

\section{Acknowledgements}

We thank the Center for the Analysis of Genome Evolution and Function (CAGEF) and Dr. Pauline Wang for significant support for the RNA-seq analysis and Dr. Huoi Ung for her technical assistance for plasmid construction. We also thank to Dr. Morten Petersen for sharing unpublished microarray data and fruitful discussion.

\section{Funding}

This project was supported by a Discovery Grant from NSERC (Natural Science and Engineering Research Council of Canada), CFI (Canadian Foundation for Innovation), and ORF (Ontario Research Fund) to KY and DD, the Robert A. Welch foundation (A-1795) to LS. This work was supported by doctoral scholarships from the Natural Sciences and Engineering Research Council (NSERC) to FYC and TAD.

\section{Availability of data and materials}

The datasets generated and analysed during the current study are available from the corresponding author on request.

\section{Authors' contributions}

FYC and TAD performed most experiments. MT, SL, and DD, conducted the $\mathrm{Y} 2 \mathrm{H}$ analysis. ST created the ERF8-OX lines. ML and BE contributed to MAPK analyses, YG did the RNA-Seq bioinformatics analysis, BL, and LS did the protoplast phosphorylation studies, WM, TAD, FYC, and KY wrote the manuscript. All authors read and approved the final manuscript.

\section{Ethics approval and consent to participate}

Not applicable.

\section{Consent for publication}

The abstract was published at Plant Biology 2018 (Montreal, QC, Canada, Abstract ID: 455888). We have contacted the American Society of Plant Biologists and confirm that we have the proper right to reuse the Abstract in this article [87].

\section{Competing interests}

The authors declare that they have no competing interests.

\section{Publisher's Note}

Springer Nature remains neutral with regard to jurisdictional claims in published maps and institutional affiliations.

\section{Author details}

${ }^{1}$ Department of Cell and Systems Biology, University of Toronto, 25 Willcocks Street, Toronto, ON M5S 3B2, Canada. ${ }^{2}$ Department of Plant Pathology and Microbiology, Institute for Plant Genomics and Biotechnology, Texas A\&M University, College Station, TX 77843, USA. ${ }^{3}$ Center for the Analysis of Genome Evolution and Function (CAGEF), University of Toronto, 25 Willcocks Street, Toronto, ON M5S 3B2, Canada. ${ }^{4}$ Michael Smith Laboratories, University of British Columbia, 2185 East Mall, Vancouver, BC V6T 1Z4, Canada. ${ }^{5}$ Present address: Department of Plant and Microbial Biology, University of Zurich, Zollikerstrasse 107, CH-8008 Zurich, Switzerland. ${ }^{6}$ Present address: Department of Life Sciences, School of Agriculture, Meiji University, 1-1-1 Higashimita, Tama-ku, Kawasaki 214-8571, japan. ${ }^{7}$ Present address: Kyoto Research Laboratories, YMC CO., LTD., 59 Yonnotsubo-cho Iwakuraminami, Sakyo-ku, Kyoto 606-0033, Japan.

Received: 5 April 2018 Accepted: 29 August 2018

Published online: 27 September 2018

\section{References}

1. Berens ML, Berry HM, Mine A, Argueso CT, Tsuda K. Evolution of Hormone Signaling Networks in Plant Defense. Annu Rev Phytopathol [Internet]. 2017; 55:annurev-phyto-080516-035544. Available from: http://www. annualreviews.org/doi/10.1146/annurev-phyto-080516-035544.

2. Vlot AC, Dempsey DA, Klessig DF. Salicylic Acid, a Multifaceted Hormone to Combat Disease. Annu Rev Phytopathol [Internet]. 2009:47:177-206. Available from: http://www.annualreviews.org/doi/10.1146/annurev.phyto. 050908.135202.

3. Sah SK, Reddy KR, Li J. Abscisic acid and abiotic stress tolerance in crop plants. Front Plant Sci. 2016;7:571

4. Vishwakarma K, Upadhyay N, Kumar N, Yadav G, Singh J, Mishra RK, et al. Abscisic Acid Signaling and Abiotic Stress Tolerance in Plants: A Review on Current Knowledge and Future Prospects. Front Plant Sci [Internet]. 2017:8 Available from: http://journal.frontiersin.org/article/10.3389/fpls.2017.00161/full.

5. Lievens L, Pollier J, Goossens A, Beyaert R, Staal J. Abscisic acid as pathogen effector and immune regulator. Front Plant Sci [Internet]. 2017:8:1-15. Available from: http://journal.frontiersin.org/article/10.3389/fpls.2017.00587/full.

6. Lim CW, Lee SC. Arabidopsis abscisic acid receptors play an important role in disease resistance. Plant Mol Biol Springer Netherlands. 2015;88:313-24.

7. Lim CW, Luan S, Lee SC. A prominent role for RCAR3-mediated ABA signaling in response to Pseudomonas syringae pv. Tomato DC3000 infection in Arabidopsis. Plant Cell Physiol. 2014;55:1691-703.

8. Melotto M, Underwood W, Koczan J, Nomura K, He SY. Plant stomata function in innate immunity against bacterial invasion. Cell. 2006;126:969-80.

9. Cao FY, Yoshioka K, Desveaux D. The roles of ABA in plant-pathogen interactions. J Plant Res [Internet]. 2011 [cited 2014 Aug 5];124:489-99. Available from: http://www.ncbi.nlm.nih.gov/pubmed/21380629.

10. Asselbergh B, De Vleesschauwer D, Höfte M. Global switches and finetuning-ABA modulates plant pathogen defense. Mol Plant-Microbe Interact [Internet]. 2008;21:709-19. Available from: http://apsjournals.apsnet. org/doi/10.1094/MPMl-21-6-0709.

11. Yasuda M, Ishikawa A, Jikumaru Y, Seki M, Umezawa T, Asami T, et al. Antagonistic interaction between systemic acquired resistance and the abscisic acid-mediated abiotic stress response in Arabidopsis. Plant Cell Online. 2008;20:1678-92

12. Mosher S, Moeder W, Nishimura N, Jikumaru Y, Joo S-H, Urquhart W, et al. The lesion-mimic mutant cpr22 shows alterations in abscisic acid signaling and abscisic acid insensitivity in a salicylic acid-dependent manner. Plant Physiol [Internet]. 2010 [cited 2014 Sep 10];152:1901-13. Available from: http://www.pubmedcentral.nih.gov/articlerender.fcgi?artid=2850030\&tool= pmcentrez\&rendertype $=$ abstract.

13. Xu J, Audenaert $\mathrm{K}$, Hofte $\mathrm{M}$, de Vleesschauwer D. Abscisic acid promotes susceptibility to the Rice leaf blight pathogen Xanthomonas oryzae pv oryzae by suppressing salicylic acid-mediated defenses. PLoS One. 2013;8.

14. Jiang C-J, Shimono M, Sugano S, Kojima M, Yazawa K, Yoshida R, et al. Abscisic acid interacts antagonistically with salicylic acid signaling pathway in RiceMagnaporthe grisea interaction. Mol Plant-Microbe Interact. 2010;23:791-8. 
15. Moeder W, Ung H, Mosher S, Yoshioka K. SA-ABA antagonism in defense responses. Plant Signal Behav. 2010;5:1231-3.

16. Couto D, Zipfel C. Regulation of pattern recognition receptor signalling in plants. Nat Rev Immunol. 2016;16:537-52.

17. Khan M, Subramaniam R, Desveaux D. Of guards, decoys, baits and traps: Pathogen perception in plants by type III effector sensors. Curr Opin Microbiol. 2016:49-55.

18. Buttner D. Behind the lines-actions of bacterial type III effector proteins in plant cells. FEMS Microbiol Rev. 2016;40:894-937.

19. Kazan K, Lyons R. Intervention of Phytohormone pathways by pathogen effectors. Plant Cell. 2014;26:2285-309.

20. de Torres-Zabala M, Truman W, Bennett MHMH, Lafforgue G, Mansfield JWJW, Rodriguez Egea P, et al. Pseudomonas syringae pv. Tomato hijacks the Arabidopsis abscisic acid signalling pathway to cause disease. EMBO J. 2007;26:1434-43.

21. Goel AK, Lundberg D, Torres MA, Matthews R, Akimoto-Tomiyama C, Farmer L, et al. The Pseudomonas syringae type III effector HopAM1 enhances virulence on water-stressed plants. Mol Plant-Microbe Interact. 2008;21:361-70.

22. Wu L, Chen H, Curtis C, Fu ZQ. Go in for the kill. Virulence. 2014;5:710-21.

23. Jones JDG, Dangl JL. The plant immune system. Nature. 2006;444:323-9.

24. Huysmans M, Lema SA, Coll NS, Nowack MK. Science Direct dying two deaths - programmed cell death regulation in development and disease Curr Opin plant biol [internet]. Elsevier Ltd. 2017;35:37-44. Available from: https://doi.org/10.1016/j.pbi.2016.11.005.

25. Müller M, Munné-Bosch S. Ethylene Response Factors: A Key Regulatory Hub in Hormone and Stress Signaling. Plant Physiol [Internet]. 2015;169:32-41. Available from: http://www.plantphysiol.org/lookup/doi/10.1104/pp.15.00677.

26. Atkinson N, Urwin P. The interaction of plant biotic and abiotic stresses: from genes to the field. J Exp Bot. 2012;63:3523-44.

27. Fujita M, Fujita Y, Noutoshi Y, Takahashi F, Narusaka Y, Yamaguchi-Shinozaki $K$, et al. Crosstalk between abiotic and biotic stress responses: a current view from the points of convergence in the stress signaling networks. Curr Opin Plant Biol. 2006;9:436-42.

28. Dey $\mathrm{S}$, Corina VA. Ethylene responsive factors in the orchestration of stress responses in monocotyledonous plants. Front Plant Sci [Internet]. 2015;6:17. Available from: http://journal.frontiersin.org/Article/10.3389/fpls.2015. 00640/abstract.

29. Huang PY, Catinot J, Zimmerli L. Ethylene response factors in Arabidopsis immunity. J Exp Bot. 2016;67:1231-41.

30. Meng X, Xu J, He Y, Yang K-Y, Mordorski B, Liu Y, et al. Phosphorylation of an ERF transcription factor by Arabidopsis MPK3/MPK6 regulates plant defense gene induction and fungal resistance. Plant Cell [Internet]. 2013;25:1126-42. Available from: http://www.plantcell.org/cgi/doi/10.1105/tpc.112.109074.

31. Wang P, Du Y, Zhao X, Miao Y, Song C-P. The MPK6-ERF6-ROS-Responsive cis-Acting Element7/GCC Box Complex Modulates Oxidative Gene Transcription and the Oxidative Response in Arabidopsis. Plant Physiol [Internet]. 2013;161:1392-408. Available from: http://www.plantphysiol.org/ cgi/doi/10.1104/pp.112.210724

32. Son GH, Wan J, Kim HJ, Nguyen XC, Chung WS, Hong JC, et al. EthyleneResponsive Element-Binding Factor 5, ERF5, Is Involved in Chitin-Induced Innate Immunity Response. Mol Plant-Microbe Interact [Internet]. 2012;25:4860. Available from: http://apsjournals.apsnet.org/doi/10.1094/MPMI-06-11-0165

33. Kagale S, Rozwadowski K. EAR motif-mediated transcriptional repression in plants: an underlying mechanism for epigenetic regulation of gene expression. Epigenetics. 2011;6:141-6.

34. Nakano T, Suzuki K, Fujimura T, Shinshi H. Genome-wide analysis of the ERF gene family. Plant Physiol. 2006;140:411-32.

35. Ohta M, Matsui K, Hiratsu K, Shinshi H, Ohme-Takagi M. Repression domains of class II ERF transcriptional repressors share an essential motif for active repression. Plant Cell. 2001;13:1959-68.

36. Koyama T, Nii H, Mitsuda N, Ohta M, Kitajima S, Ohme-Takagi M, et al. A Regulatory Cascade Involving Class II ETHYLENE RESPONSE FACTOR Transcriptional Repressors Operates in the Progression of Leaf Senescence. Plant Physiol [Internet]. 2013;162:991-1005. Available from: http://www. plantphysiol.org/cgi/doi/10.1104/pp.113.218115

37. Mcgrath KC, Dombrecht B, Manners JM, Schenk PM, Edgar Cl, Udvardi MK, et al. Repressor- and Activator-Type Ethylene Response Factors Functioning in Jasmonate Signaling and Disease Resistance Identified via a GenomeWide Screen of Arabidopsis Transcription Factor Gene Expression [ w ]. 2005;139:949-59.
38. Maruyama Y, Yamoto N, Suzuki Y, Chiba Y, Yamazaki K. Ichi, Sato T, et al. the Arabidopsis transcriptional repressor ERF9 participates in resistance against necrotrophic fungi. Plant Sci [internet]. Elsevier Ireland Ltd. 2013;213:79-87. Available from: https://doi.org/10.1016/j.plantsci.2013.08.008

39. Song C-P, Agarwal M, Ohta M, Guo Y, Halfter U, Wang P. Role of an Arabidopsis AP2 / EREBP-type transcriptional repressor in abscisic acid and drought stress responses. Plant Cell. 2005;17:2384-96.

40. Li Z, Zhang L, Yu Y, Quan R, Zhang Z, Zhang H, et al. The ethylene response factor AtERF11 that is transcriptionally modulated by the bZIP transcription factor HY5 is a crucial repressor for ethylene biosynthesis in Arabidopsis. Plant J. 2011;68:88-99.

41. Zhou X, Zhang Z-L, Yusuke J, Qiu K, Park J, Nam EA, et al. ERF11 Promotes Internode Elongation by Activating Gibberellin Biosynthesis and Signaling Pathways in Arabidopsis. Plant Physiol [Internet]. 2016;pp.00154.2016. Available from: http://www.plantphysiol.org/lookup/doi/10.1104/pp.16.00154

42. Lumba S, Toh S, Handfield LF, Swan M, Liu R, Youn JY, et al. A mesoscale abscisic acid hormone interactome reveals a dynamic signaling landscape in arabidopsis. Dev Cell. 2014;29:360-72.

43. Eschen-Lippold L, Bethke G, Palm-Forster M, Pecher P, Bauer N, Glazebrook J, et al. MPK1 1 - a fourth elicitor-responsive mitogen-activated protein kinase in Arabidopsis thaliana. Plant Signal Behav. 2012;7:1203-5.

44. Bethke G, Pecher P, Eschen-Lippold L, Tsuda K, Katagiri F, Glazebrook J, et al. Activation of the Arabidopsis thaliana Mitogen-Activated Protein Kinase MPK11 by the Flagellin-Derived Elicitor Peptide, flg22. Mol Plant-Microbe Interact [Internet]. 2012;25:471-80. Available from: http://apsjournals.apsnet. org/doi/10.1094/MPMI-11-11-0281

45. Petersen M, Brodersen $P$, Naested $H$, Andreasson $E$, Lindhart $U$, Johansen $B$, et al. Arabidopsis MAP Kinase 4 Negatively Regulates Systemic Acquired Resistance. 2000;103:1111-20.

46. Berriri S, Garcia a. V, Frei dit Frey N, Rozhon W, Pateyron S, Leonhardt N, et al. Constitutively Active Mitogen-Activated Protein Kinase Versions Reveal Functions of Arabidopsis MPK4 in Pathogen Defense Signaling. Plant Cell. 2012;24:1-14.

47. Kong Q, Qu N, Gao M, Zhang Z, Ding X, Yang F, et al. The MEKK1-MKK1/ MKK2-MPK4 Kinase Cascade Negatively Regulates Immunity Mediated by a Mitogen-Activated Protein Kinase Kinase Kinase in Arabidopsis. Plant Cell [Internet]. 2012;24:2225-36. Available from: http://www.plantcell.org/cgi/doi/ 10.1105/tpc.112.097253

48. Narsai R, Law SR, Carrie C, Xu L, Whelan J. In-Depth Temporal Transcriptome Profiling Reveals a Crucial Developmental Switch with Roles for RNA Processing and Organelle Metabolism That Are Essential for Germination in Arabidopsis. Plant Physiol [Internet]. 2011;157:1342-62. Available from: http://www.plantphysiol.org/cgi/doi/10.1104/pp.111.183129

49. Wu L, Chen H, Curtis C, Fu ZQ. Go in for the kill: how plants deploy effectortriggered immunity to combat pathogens. Virulence. 2014;5:710-21.

50. Mur LAJ, Kenton P, Lloyd AJ, Ougham H, Prats E. The hypersensitive response; The centenary is upon us but how much do we know? J Exp Bot. 2008:501-20.

51. Moeder W, Yoshioka K. Environmental Sensitivity in Pathogen Resistant Arabidopsis Mutants. Signal Crosstalk Plant Stress Responses. 2009:113-35.

52. Ogata T, Kida Y, Tochigi M, Matsushita Y. Analysis of the cell death-inducing ability of the ethylene response factors in group VIII of the AP2/ERF family. Plant Sci [internet]. Elsevier Ireland Ltd. 2013;209:12-23. Available from: https://doi.org/10.1016/j.plantsci.2013.04.003

53. Ogata T, Kida Y, Arai T, Kishi Y, Manago Y, Murai M, et al. Overexpression of tobacco ethylene response factor NtERF3 gene and its homologues from tobacco and rice induces hypersensitive response-like cell death in tobacco. J Gen Plant Pathol. 2012;78:8-17.

54. Yang Z, Tian L, Latoszek-Green M, Brown D, Wu K. Arabidopsis ERF4 is a transcriptional repressor capable of modulating ethylene and abscisic acid responses. Plant Mol Biol. 2005;58:585-96.

55. Yang L, Teixeira PJPL, Biswas S, Finkel OM, He Y, Salas-Gonzalez I, et al. Pseudomonas syringae type III effector HopBB1 promotes host transcriptional repressor degradation to regulate Phytohormone responses and virulence. Cell Host Microbe. 2017;21:156-68.

56. Ohta M. Repression domains of class II ERF transcriptional repressors share an essential motif for active repression. Plant Cell Online [Internet]. 2001;13: 1959-68. Available from: http://www.plantcell.org/content/13/8/1959.

57. Kagale S, Links MG, Rozwadowski K. Genome-Wide Analysis of EthyleneResponsive Element Binding Factor-Associated Amphiphilic Repression Motif-Containing Transcriptional Regulators in Arabidopsis. Plant Physiol 
[Internet]. 2010;152:1109-34. Available from: http:/www.plantphysiol.org/ cgi/doi/10.1104/pp.109.151704

58. Hamel L-P, Benchabane M, Nicole M-C, Major IT, Morency M-J, Pelletier G, et al. Stress-responsive mitogen-activated protein kinases interact with the EAR motif of a poplar zinc finger protein and mediate its degradation through the 265 proteasome. Plant Physiol. 2011;157:1379-93.

59. Lee JS, Huh KW, Bhargava A, Ellis BE. Comprehensive analysis of proteinprotein interactions between Arabidopsis MAPKs and MAPK kinases helps define potential MAPK signalling modules. Plant Signal Behav [Internet]. 2008:3:1037-41. Available from: http://www.pubmedcentral.nih.gov/ articlerender.fcgi?artid $=2634456 \&$ tool $=$ pmcentrez\&rendertype $=$ abstract

60. Durek P, Schmidt R, Heazlewood JL, Jones A, MacLean D, Nagel A, et al. PhosPhAt: the Arabidopsis thaliana phosphorylation site database. An update Nucleic Acids Res. 2009;38:828-34.

61. Li B, Jiang S, Yu X, Cheng C, Chen S, Cheng Y, et al. Phosphorylation of Trihelix transcriptional repressor ASR3 by MAP KINASE4 negatively regulates Arabidopsis immunity. Plant Cell [Internet]. 2015;27:839-56. Available from: http://www.plantcell.org/lookup/doi/10.1105/tpc.114.134809

62. Roberts M, Tang S, Stallmann A, Dangl JL, Bonardi V. Genetic requirements for signaling from an autoactive plant NB-LRR intracellular innate immune receptor. PLoS Genet. 2013:9

63. Shah J. The salicylic acid loop in plant defense. Curr Opin Plant Biol. 2003;6:365-71.

64. Meng X, Zhang S. MAPK cascades in plant disease resistance signaling Annu Rev Phytopathol. 2013;51:245-66.

65. Qiu J-L, Fiil BK, Petersen K, Nielsen HB, Botanga CJ, Thorgrimsen S, et al. Arabidopsis MAP kinase 4 regulates gene expression through transcription factor release in the nucleus. EMBO J. 2008:27:2214-21.

66. Bethke G, Unthan T, Uhrig JF, Poschl Y, Gust AA, Scheel D, et al. Flg22 regulates the release of an ethylene response factor substrate from MAP kinase 6 in Arabidopsis thaliana via ethylene signaling. Proc Natl Acad Sci [Internet]. 2009;106:8067-72. Available from: http://www.pnas.org/cgi/doi/ 10.1073/pnas.0810206106

67. Li G, Meng X, Wang R, Mao G, Han L, Liu Y, et al. Dual-level regulation of ACC synthase activity by MPK3/MPK6 cascade and its downstream WRKY transcription factor during ethylene induction in arabidopsis. PLoS Genet. 2012;8

68. Fagundes D, Bohn B, Cabreira C, Leipelt F, Dias N, Bodanese-Zanettini MH, et al. Caspases in plants: metacaspase gene family in plant stress responses. Funct. Integr. Genomics. 2015:639-49.

69. Watanabe N, Lam E. Calcium-dependent activation and autolysis of arabidopsis metacaspase 2d. J Biol Chem. 2011;286:10027-40.

70. Bruggeman Q, Raynaud C, Benhamed M, Delarue M. To die or not to die? Lessons from lesion mimic mutants. Front Plant Sci [Internet]. 2015; 6:1-22. Available from: http://journal.frontiersin.org/article/10.3389/fpls. 2015.00024/abstract

71. Moeder W, Yoshioka K. Lesion mimic mutants: a classical, yet still fundamental approach to study programmed cell death. Plant Signal Behav. 2008:3:764-7.

72. Zhu Z, Xu F, Zhang Y, Cheng YT, Wiermer M, Li X, et al. Arabidopsis resistance protein SNC1 activates immune responses through association with a transcriptional corepressor. Proc Natl Acad Sci [Internet]. 2010;107: 13960-5. Available from: http://www.pnas.org/cgi/doi/10.1073/pnas. 1002828107

73. Lyons R, Iwase A, Gänsewig T, Sherstnev A, Duc C, Geoffrey J. FPA regulates flg22-triggered responses and transcription factor activity by alternative polyadenylation.

74. Gao M, Liu J, Bi D, Zhang Z, Cheng F, Chen S, et al. MEKK1, MKK1/MKK2 and MPK4 function together in a mitogen-activated protein kinase cascade to regulate innate immunity in plants. Cell Res. 2008;18:1190-8.

75. Andreasson E, Jenkins T, Brodersen P, Thorgrimsen S, Petersen NHT, Zhu S, et al. The MAP kinase substrate MKS1 is a regulator of plant defense responses. EMBO J. 2005;24:2579-89.

76. Roux ME, Rasmussen MW, Palma K, Lolle S, Mateu A, Bethke G, et al. The mRNA decay factor PAT 1 functions in a pathway including MAP kinase 4 and immune receptor SUMM 2. 2015;1-16.

77. Zhang Z, Wu Y, Gao M, Zhang J, Kong Q, Liu Y, et al. Disruption of PAMPinduced MAP kinase cascade by a pseudomonas syringae effector activates plant immunity mediated by the NB-LRR protein SUMM2. Cell Host Microbe. Elsevier Inc: 2012:11:253-63.
78. Dephoure N, Gould KL, Gygi SP, Kellogg DR, Drubin DG. Mapping and analysis of phosphorylation sites : a quick quide for cell biologists 2013;24

79. Causier B, Ashworth M, Guo W, Davies B. The TOPLESS Interactome: A Framework for Gene Repression in Arabidopsis. Plant Physiol [Internet]. 2012;158:423-38. Available from: http://www.plantphysiol.org/cgi/doi/10 1104/pp.111.186999

80. Der Does D Van, Hickman R, Jansen W, Van Verk MC, Proietti S, Lorenzo O, et al. Assessing the role of ETHYLENE RESPONSE FACTOR transcriptional repressors in salicylic acid-mediated suppression of jasmonic acidresponsive genes lotte caarls1,5. Plant Cell Physiol. 2017;58:266-278.

81. Van den Broeck L, Dubois M, Vermeersch M, Storme V, Matsui M, Inzé D. From network to phenotype: the dynamic wiring of an Arabidopsis transcriptional network induced by osmotic stress. Mol Syst Biol [Internet]. 2017;13:-961. Available from: http://msb.embopress.org/lookup/doi/10. 15252/msb.20177840

82. Olvera-Carrillo $Y$, Van Bel M, Van Hautegem T, Fendrych M, Van Durme M, Huysmans $\mathrm{M}$, et al. A conserved core of PCD indicator genes discriminates developmentally and environmentally induced programmed cell death in plants. Plant Physiol [Internet]. 2015;169:pp.00769.2015. Available from: http://www.plantphysiol.org/lookup/doi/10.1104/pp.15.00769

83. Yu C-P, Lin J-J, Li W-H. Positional distribution of transcription factor binding sites in Arabidopsis thaliana. Sci Rep [Internet]. Nat Publ Group. 2016:6: 25164. Available from: http://www.nature.com/articles/srep25164

84. DeFalco TA, Marshall CB, Munro K, Kang H-G, Moeder W, Ikura M, et al. Multiple Calmodulin-binding Sites Positively and Negatively Regulate Arabidopsis CYCLIC NUCLEOTIDE-GATED CHANNEL12. Plant Cell [Internet]. 2016;28:tpc.00870.2015. Available from: http://www.plantcell.org/lookup/doi/ 10.1105/tpc.15.00870

85. Laflamme B, Middleton M, Lo T, Desveaux D, Guttman DS. Image-Based Quantification of Plant Immunity and Disease. Mol Plant-Microbe Interact [Internet]. 2016;29:MPMI-07-16-0129. Available from: http://apsjournals. apsnet.org/doi/10.1094/MPMI-07-16-0129-TA

86. Robinson MD, Mccarthy DJ, Smyth GK edgeR : a Bioconductor package for differential expression analysis of digital gene expression data 2010;26:139140.

87. Moeder, W., Cao, F.Y., DeFalco, T.A., Li, B., Gong, Y., Lumba, S., Toh, S., Shan, L., Ellis, B., Desveaux, D., Yoshioka, K. Arabidopsis ETHYLENE RESPONSE FACTOR 8 (ERF8) has dual functions in ABA signaling and immunity. Plant Biology 2018, Montreal, QC, Canada, July 14-18, 2018.

Ready to submit your research? Choose BMC and benefit from:

- fast, convenient online submission

- thorough peer review by experienced researchers in your field

- rapid publication on acceptance

- support for research data, including large and complex data types

- gold Open Access which fosters wider collaboration and increased citations

- maximum visibility for your research: over $100 \mathrm{M}$ website views per year

At BMC, research is always in progress.

Learn more biomedcentral.com/submissions 